\title{
Radioembolization of hepatic lesions from a radiobiology and dosimetric perspective
}

\section{Marta Cremonesi ${ }^{1}{ }^{*}$, Carlo Chiesa $^{2}$, Lidia Strigari ${ }^{3}$, Mahila Ferrari ${ }^{1}$, Francesca Botta ${ }^{1}$, Francesco Guerriero ${ }^{1}$, Concetta De Cicco ${ }^{4}$, Guido Bonomo ${ }^{1}$, Franco Orsi ${ }^{1}$, Lisa Bodei ${ }^{1}$, Amalia Di Dia ${ }^{5}$, Chiara Maria Grana ${ }^{1}$ and Roberto Orecchia ${ }^{1}$}

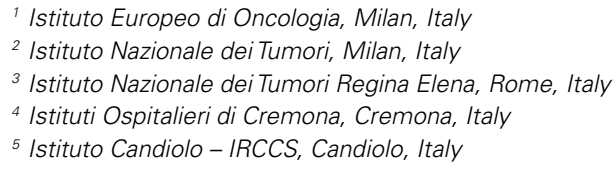

\section{Edited by:}

Georgios S. Limouris, Athens University Medical Faculty, Greece

Reviewed by:

Luigi Aloj, IRCCS Istituto Nazionale

Tumori Fondazione G. Pascale, Italy Georgios S. Limouris, Athens

University Medical Faculty, Greece

\section{${ }^{*}$ Correspondence:}

Marta Cremonesi, Istituto Europeo di Oncologia, via Ripamonti, 435, Milano 20141, Italy

e-mail: marta.cremonesi@ieo.it
Radioembolization (RE) of liver cancer with ${ }^{90}$ Y-microspheres has been applied in the last two decades with notable responses and acceptable toxicity. Two types of microspheres are available, glass and resin, the main difference being the activity/sphere. Generally, administered activities are established by empirical methods and differ for the two types. Treatment planning based on dosimetry is a prerogative of few centers, but has notably gained interest, with evidence of predictive power of dosimetry on toxicity, lesion response, and overall survival (OS). Radiobiological correlations between absorbed doses and toxicity to organs at risk, and tumor response, have been obtained in many clinical studies. Dosimetry methods have evolved from the macroscopic approach at the organ level to voxel analysis, providing absorbed dose spatial distributions and dose-volume histograms $(D V H)$. The well-known effects of the external beam radiation therapy (EBRT), such as the volume effect, underlying disease influence, cumulative damage in parallel organs, and different tolerability of re-treatment, have been observed also in RE, identifying in EBRT a foremost reference to compare with. The radiobiological models - normal tissue complication probability and tumor control probability - and/or the style (DVH concepts) used in EBRT are introduced in RE. Moreover, attention has been paid to the intrinsic different activity distribution of resin and glass spheres at the microscopic scale, with dosimetric and radiobiological consequences. Dedicated studies and mathematical models have developed this issue and explain some clinical evidences, e.g., the shift of dose to higher toxicity thresholds using glass as compared to resin spheres. This paper offers a comprehensive review of the literature incident to dosimetry and radiobiological issues in $R E$, with the aim to summarize the results and to identify the most useful methods and information that should accompany future studies.

Keywords: radioembolization, liver tumors, ${ }^{90} \mathrm{Y}$-microspheres, dosimetry, radiobiology

\section{INTRODUCTION}

In the past two decades, radioembolization (RE) with ${ }^{90} \mathrm{Y}$ microspheres has emerged as a safe and efficacious treatment modality for unresectable primary and secondary liver malignancies. The rationale is based on the fact that both the primary and the secondary tumor $(T)$ lesions in the liver receive their blood supply primarily from the hepatic artery, whereas non-tumoral liver (NL) is almost excluded from the hepatic artery and fed essentially via the portal vein. Spheres are injected in the hepatic artery and become trapped within the $T$ microvasculature, so that they selectively deliver radiation to the $T$ whilst sparing normal tissue. In NL, microspheres remain confined to the portal tracts (1). This locoregional technique represents a good option to irradiate liver $T$ as compared to external beam radiation therapy (EBRT), this latter being limited by the high radiosensitivity of the liver parenchyma. A further advantage of RE is that it can be combined with other therapy modalities that are under study in several phase III multicentre trials (2). Two types of microspheres are commercially available, the glass spheres [Therasphere ${ }^{\circledR}$ BTG, Ontario, Canada (3)] and the resin spheres (SIR-Spheres ${ }^{\circledR}$, SIRTex Medical Limited Sydney, Australia, http://www.sirtex.com) (4). The activity to be administered is chosen using empirical or raw dosimetric methods, depending on the types of spheres, while fully dosimetric treatment planning is very rarely applied. Overall, significant response rates have been observed in patients with unresectable primary or secondary hepatic malignancies, with a limited number of side effects (5-8). However, no study was specifically accomplished to enlighten the power of a fully dosimetric treatment planning: increased efficacy and reduced toxicity. In nuclear medicine treatment, the importance of dosimetry to comprehend the radiobiological effects is growing and documented by the increased number of papers addressing dosimetry in the 
recent literature (9-13). In RE, the essential dosimetry methods based on compartmental models have been more traditionally applied and have proved correlations between absorbed doses and effects. Even if still in few centers, dosimetry planning guides RE treatment (13-15). Specific experimental studies and mathematical modeling at the microscopic level have provided enlightening information for the understanding of macroscopic observations, such as the RE-induced liver disease (REILD) and the different behavior of glass versus resin spheres, with the apparent higher tolerability of RE with glass spheres and higher absorbed doses associated to $T$ response $(12-14,16)$. More recently, 3D voxel dosimetry methods have been applied to RE, providing dose distribution maps and dose-volume histograms (DVH). This allowed to apply radiobiological models to predict the probability of toxicity, normal tissue complication probability (NTCP), and $T$ response, tumor control probability (TCP). In regard to the clinical context, outcomes such as the volume effect, the influence of the functional reserve and/or concomitant therapies, with higher tolerability of re-treatment, reflect a further similarity with EBRT, which can be identified as a foremost reference to compare with, although differences with EBRT exist and must be considered. The aim of this study is to comprehensively review the literature addressing these issues from a radiobiological perspective.

\section{TWO TYPES OF ${ }^{90} Y$-MICROSPHERES}

${ }^{90} \mathrm{Y}$ is a pure $\beta$-emitter radionuclide with maximum and average $\beta$-energies of $2.28 \mathrm{MeV}$ and $934 \mathrm{keV}$, respectively, corresponding to a maximum and average path lengths in soft tissue of 11 and $4.1 \mathrm{~mm}$, respectively. It has a half-life of $64.2 \mathrm{~h}$ and it decays into the stable element ${ }^{90} \mathrm{Zr}$. There is also a minor branch of the decay to a $\mathrm{O}+$ first excited state of ${ }^{89} \mathrm{Zr}$ at $1.78 \mathrm{MeV}$, which is followed by a $\beta+\beta$-emission. Although the branching ratio is very low $\left(32 \times 10^{-6}\right)$, it is most important as it allows ${ }^{90} \mathrm{Y}$-microspheres PET imaging after RE $(17,18)$. The release of the absorbed dose occurs in the surrounding tissue according to the ${ }^{90} \mathrm{Y}$-range.

The main characteristics of glass and resin spheres are summarized in Table 1. Microspheres are biocompatible but not biodegradable or metabolized. The most relevant difference between the two types of spheres is the activity per sphere, which is much higher in the glass spheres $(\sim 2500 \mathrm{~Bq})$ than in resin ones ( $50 \mathrm{~Bq})$ (see also section Activity Distribution at the Microscopic Level). A further difference between resin and glass is the shelf-life, being 1 day for resin spheres, and 12 days for glass spheres. This implies that the same number of resin spheres/GBq is always injected, while the number of glass spheres/GBq increases according to ${ }^{90} \mathrm{Y}$ physical decay (time interval left between preparation and administration). Overall, for a same activity, the ratio between the number of resin and glass spheres can vary from 50 $(2500 \mathrm{~Bq} / 50 \mathrm{~Bq})$ to $2.2[2500 \mathrm{~Bq} /(22.6 \times 50) \mathrm{Bq}]$. This point has interesting dosimetric consequences that will be described later on (section Activity Distribution at the Microscopic Level).

Flow stasis, making the injection of the whole planned activity impossible, has been observed during resin microspheres administration (especially in super-selective treatments), while it has never been reported with glass microspheres $(19,20)$. This is probably due to the very high number of particles, and suggests a possible role of embolization in the case of resin spheres (see also section Activity Distribution at the Microscopic Level).

\section{ADMINISTERED ACTIVITY}

The amount of activity to be administered should ideally be established accounting for the major factors that may influence therapy

Table 1 | Characteristics of ${ }^{90} \mathrm{Y}$-microspheres $(6,20,24)$.

\begin{tabular}{|c|c|c|}
\hline Commercial name & SIR-Spheres $®$ & TheraSphere $®$ \\
\hline Manufacturer & Sirtex Medical, Lane Cove Australia & Therasphere BTG, Ontario, Canada \\
\hline Material & Resin & Glass \\
\hline${ }^{90}$ Y sphere production & Bound to resin, attached to sphere surface & Embedded in a glass matrix \\
\hline Particle size ( $\mu \mathrm{m})$ & $32.5 \pm 2.5$ (range: $20-60$ ) & $25 \pm 5$ (range: $20-30)$ \\
\hline Activity per sphere (Bq) & 50 (range: 40-80) & 2500 at the reference time \\
\hline Number of spheres per GBq (million) & 20 (mean) & 0.4 at the reference time \\
\hline Shelf-life & 1 day & 12 days \\
\hline Specific gravity & $\operatorname{Low}(1.6 \mathrm{~g} / \mathrm{cc})$ & High $(3.6 \mathrm{~g} / \mathrm{cc})$ \\
\hline Embolic effect & Moderate & Mild \\
\hline Activity available (GBq) & 3 & From 3 to 20, with step 0.5 \\
\hline Number of spheres in $3 \mathrm{GBq}$ & 40-80 million & 1.2 million at the time of calibration \\
\hline Approved for & $\begin{array}{l}\text { USA: HCC; Outside USA (especially Europe } \\
\text { and Australia): unresectable liver tumors } \\
\text { (HCC and metastases) }\end{array}$ & $\begin{array}{l}\text { USA: colorectal carcinoma Outside } \\
\text { USA (especially Europe and Australia): } \\
\text { HCC and metastases }\end{array}$ \\
\hline Handling for dispensing & Required & Not possible \\
\hline Splitting one vial for two or more administrations & Possible & Not possible \\
\hline Necessity of contrast medium guidance during administration & Yes & No \\
\hline
\end{tabular}


outcome. Among these, there are the NL involvement, the tumor uptake, the possible side effects to healthy tissues, the baseline patients' condition, and the absorbed dose. More rarely, the activity to be injected is based on dosimetric evaluations (13-15, 21, 22). Table 2 summarizes the methods proposed, equations, constraints, and essential pros and cons for the two types of microspheres.

For resin microspheres, three methods (i, ii, and iii) have been suggested by the manufacturer (4) to decide the ${ }^{90} \mathrm{Y}$ activity. In common, they have the indication of reducing the prescribed activity depending on the lung shunt (LS) fraction, in order to lower the radiation risks to the lungs.

(i) The empirical method recommends three different activities based on $T$ involvement (Table 2). It is not an individualized approach because it does not account for the volume of the NL involved in the irradiation, and thus its tolerability. It is worth noting that with the highest activity, the absorbed doses to the lungs and to NL are within $\sim 18$ and $\sim 83 \mathrm{~Gy}$, as derived using the OLINDA/EXM software for a standard patient (23). Note that among 28 patients dead at least in part because of liver toxicity over 680 treated with resin spheres, 21 from a single center were administered according to this method (24).

(ii) The body surface area (BSA) method, still empirical, takes into account the patient's BSA, the $T$ mass $\left(M_{\mathrm{T}}\right)$ and the NL mass $\left(M_{\mathrm{NL}}\right)$, assuming a correlation between BSA and $T$. However, there is experimental evidence that the BSA does not correlate with $M_{\mathrm{L}}$ or with $T$ involvement (25). Even if it includes some individual parameters, it should not be misconstrued in terms of tailored evaluation, as it neglects the individual $T / \mathrm{NL}$ avidity ratio, which is patient specific, even lesion specific (22). Activities remain usually within $2.5 \mathrm{GBq}$ (25). This is the method most commonly used for RE with resin spheres (24).

(iii) The multi-compartmental MIRD macrodosimetry method (also known as partition model) $(26,27)$ calculates the activity to be administered using the MIRD equations, once an absorbed dose limit is prescribed to NL, but no liver toxicity nor efficacy threshold accompanied this methodology. The lung safety is also considered, with a specific absorbed

Table 2 | Methods to determine the activity to be injected according to device user manual.

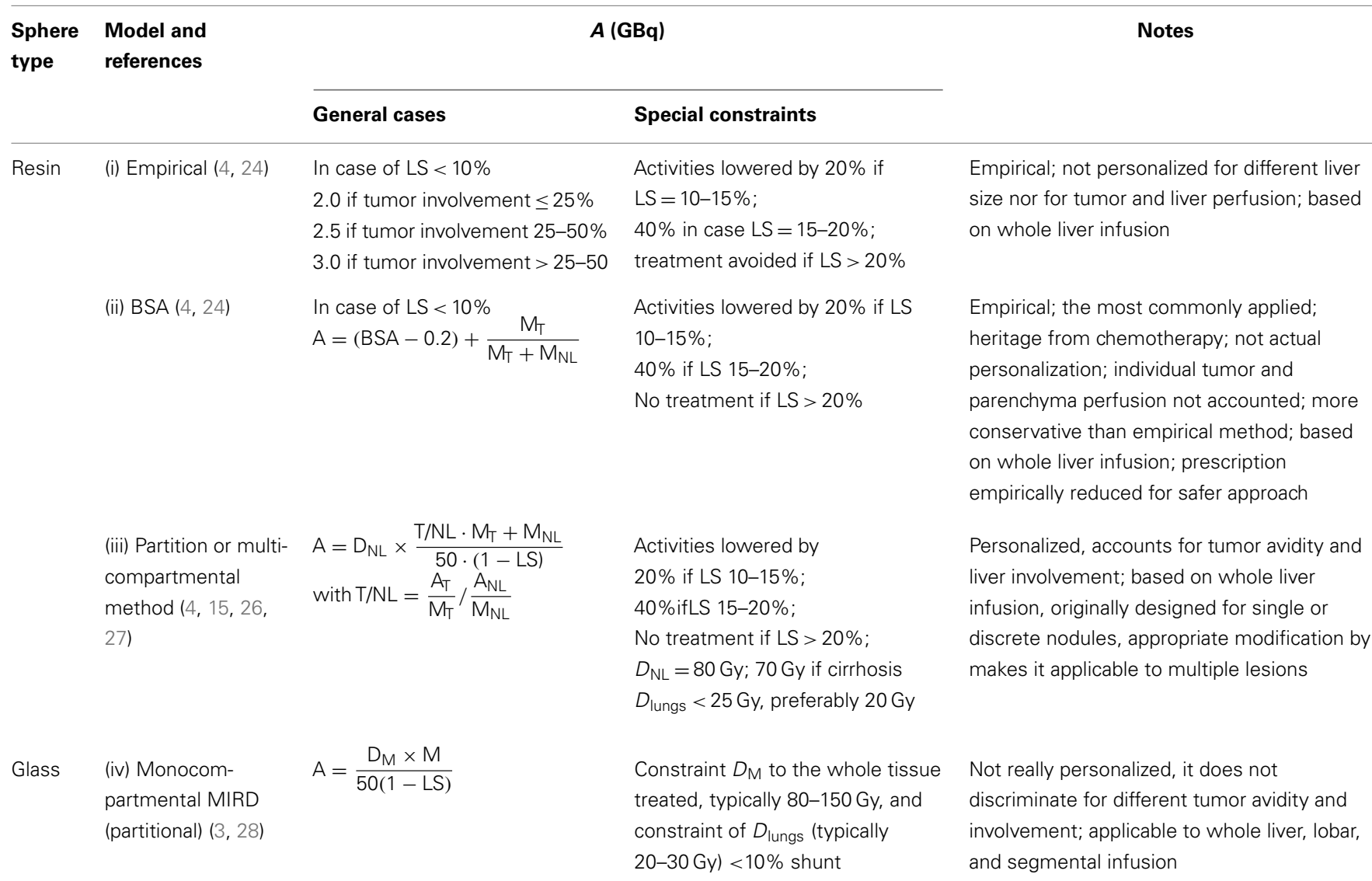

A, activity (GBq); $L S$, lung shunt fraction; BSA, body surface area; $A$, activity to be administered (GBq); $M_{T}$, tumor mass (kg); NL, non-tumoral liver; $T$, tumor; $M_{N L}, N L$ mass (kg); $A_{T}, T$ uptake (GBq); $A_{N L}, N L$ uptake (GBq); T/NL, T over NL uptake ratio; $D_{N L}$, absorbed dose limit prescribed for NL (Gy); $D_{\text {lungs, }}$ absorbed dose limit prescribed for the lungs (Gy); 50 , conversion factor $(G y \times k g / G B q)$ for ${ }^{90} Y$ for a standard patient; $M$, whole mass $\left(M_{N L}+M_{T}\right)(k g)$; $D_{M}$, absorbed dose limit prescribed for $M$. 
dose constraint. The equation takes into account the $T / \mathrm{NL}$ uptake ratio, the liver involvement $\left(M_{\mathrm{T}}\right.$ and $\left.M_{\mathrm{NL}}\right)$ and the possible LS.

One single method is proposed for glass spheres by the manufacturer:

(iv) The mono-compartmental MIRD macrodosimetry model relies on a simplified dosimetry equation of the multicompartmental model $(3,7,28)$ in which an absorbed dose to the whole liver or lobe $\left(D_{\mathrm{M}}\right)$ - typically ranging from 80 to $150 \mathrm{~Gy}$ - is empirically prescribed as averaged on the whole treated liver or lobe, including the $T$, of mass $M=M_{\mathrm{T}}+M_{\mathrm{NL}}$. So, a uniform activity distribution is assumed and absorbed doses to $T$ and NL are not separately calculated. No distinction is made for different tumor involvement and avidity.

The methods (i), (ii), and (iv) are appealing for their simplicity but clearly suboptimal. This has led to possible under-treatments, compromising efficacy, or over-treatments, inducing unwanted effects. The multi-compartmental dosimetric model (iii) provides a more scientifically sound basis for the activity determination, although it demands a confident identification of absorbed doses ensuring liver tolerability. Moreover, it relies on the possibility to simulate therapy.

\section{SIMULATION OF THE TREATMENT}

The therapy session is generally simulated with intra-arterial administration of ${ }^{99 \mathrm{~m}}$ Tc-MacroAggregate Albumin ( $\left.{ }^{99 \mathrm{~m}} \mathrm{Tc}-\mathrm{MAA}\right)$ that should mimic the vascular distribution pattern of ${ }^{90} \mathrm{Y}-$ microspheres. The simulation is mandatory to evaluate the possible LS fraction and to exclude gastrointestinal (GI) shunt. ${ }^{99 \mathrm{~m}} \mathrm{Tc}$ MAA is also used to analyze, at least visually (29), the T/NL uptake ratio and to evaluate dosimetry in the frame of individualized treatment planning. This is based on the hypothesis that ${ }^{99} \mathrm{~m}$ Tc-MAA and ${ }^{90} \mathrm{Y}$-microspheres have identical intra-hepatic distribution, due to comparable size (10-100 $\mu \mathrm{m}$ diameter) and density $(12,26)$. However, the adequacy of this hypothesis is under debate, since the number/dimension of injected resin, glass, and MAA particles differ. The number of injected resin spheres greatly differ, being $\sim 300$ times higher than the number of ${ }^{99 \mathrm{~m}} \mathrm{Tc}$ MAA particles and $~ 50$ times higher than the number of glass spheres (12). Thus, a possible higher embolic effect of resin spheres is expected as compared to glass spheres, versus no significant embolic effect of MAA particles on the hepatic arterial circulation. Other differences may rise from different micro-catheter tip placement and regional blood flow changes between simulation and RE. These points have created concern about the predictive value of ${ }^{99 \mathrm{~m}}$ Tc-MAA scintigraphy for NL and $T$ dosimetry. Results from the literature are controversial. Wondergem et al. (30) found discrepancies between ${ }^{99 \mathrm{~m}}$ Tc-MAA images simulating $\mathrm{RE}$ and ${ }^{90} \mathrm{Y}$-Bremsstrahulg SPECT images - post-RE - in patients with a mismatch in catheter tip positioning during administrations. This study highlights the importance of this maneuver when using MAA images as predictive of microsphere distribution. Knesaurek et al. (31) found poor correlation in some of the patients analyzed. The same group confirmed the critical role of catheter repositioning in combination with proximity to an arterial bifurcation (32). In a study object of discussion, Ulrich et al. claimed a low predictivity of MAA based on visual examination of MAA and ${ }^{90}$ Y-Bremsstrahulg SPECT images $(29,33)$. On the other hand, despite undeniable differences, the significance of ${ }^{99} \mathrm{~m}$ Tc-MAA in the treatment planning of resin spheres has been shown $(14,33$, 34). Strigari et al. (16) stated that ${ }^{99 \mathrm{~m}} \mathrm{Tc}-\mathrm{MAA}$ SPECT images of the abdomen were sufficiently predictive of the ${ }^{90} \mathrm{Y}-\mathrm{SIR}$ sphere distribution in more than $80 \%$ of patients. Flamen et al. (35) reported that MAA and ${ }^{90} \mathrm{Y}$ imaging did correspond in all cases.

For glass spheres, the problem is less evident, thanks to the lower number of injected particles. The capability of MAA based lesion dosimetry to predict response and even overall survival (OS) has been shown (14), meaning that in the majority of patients the simulation is worthwhile (33). Chiesa et al. (12) compared ${ }^{99 \mathrm{~m}} \mathrm{Tc}$ MAA and ${ }^{90} \mathrm{Y}-S P E C T$ in 35 patients treated with glass spheres. In $71 \%$ of cases, distributions were similar. In $8 / 35$ patients, differences were marked, and uncertain in $6 \%$. Discrepancies were attributed mostly to intentional changes in catheter positioning, while in 2 patients $(6 \%)$ to the different specific weight of glass microspheres with respect to MAA. Kao et al. (36) retrospectively analyzed ${ }^{99 \mathrm{~m}} \mathrm{Tc}-\mathrm{MAA}-\mathrm{SPECT}$ and ${ }^{90} \mathrm{Y}$-PET images, and compared the mean $T$ absorbed doses. Excellent correlation was found in selected patients, with a relative error ranging from $-1.2 \%$ to $+13.2 \%$. Preliminary results from direct DVH comparison between ${ }^{99 \mathrm{~m}} \mathrm{Tc}-\mathrm{MAA}-\mathrm{SPECT}$ and ${ }^{90} \mathrm{Y}$-PET have been presented to assess the role of treatment planning based on simulation images $(37,38)$. Several authors showed a good correlation between the $T$ absorbed dose based on the partition model and the response to ${ }^{90} \mathrm{Y}$-microspheres in metastatic disease, as well as in HCC (12, 14, 22, 35, 39-41). In particular, Garin et al. (14) have shown that dosimetry based on ${ }^{99 \mathrm{~m}}$ Tc-MAA-SPECT not only predicts $T$ response but also OS in patients with HCC. ${ }^{99 \mathrm{~m}} \mathrm{Tc}-\mathrm{MAA}$ scintigraphy is a relevant source of information for patient recruitment and RE treatment feasibility. Provided that both the tracer and microspheres are injected under the same condition, ${ }^{99 \mathrm{~m}} \mathrm{Tc}-\mathrm{MAA}$ SPECT-CT gives an accurate description of the microspheres distribution in $T$, as well as in normal tissues, predicting the shunt to extra-hepatic lungs and the GI tract $(36,42,43)$.

\section{VERIFICATION OF THE TREATMENT}

The evaluation of the actual biodistribution in RE is of utmost importance in order to verify the ${ }^{99 \mathrm{~m}} \mathrm{Tc}$-MAA prediction. A first option is to acquire Bremsstrahlung-SPECT images (12, 16, 43, 44 ), although difficulties raise from the poor-quality images that could lead to inaccurate quantification of microsphere biodistribution. Some authors have shown the possibility to obtain impressive imaging improvements by applying appropriate corrections for scatter, attenuation, and response of the system (45, 46) or a special collimator (47), but the suggested methods are applied only in very few research centers since they require very careful calibration and experience. Alternatively, Lhommel et al. (17), followed by other authors (18, 48-50), have shown that $\mathrm{PET} / \mathrm{CT}$ scanners are able to provide good-quality ${ }^{90} \mathrm{Y}$ images when radioactivity is highly concentrated, as in RE, and that accurate patient dosimetry is attainable. A further step is represented by the $3 \mathrm{D}$ analysis at the voxel level. Several authors have elaborated pre-treatment ${ }^{99 \mathrm{~m}} \mathrm{Tc}-\mathrm{MAA}-\mathrm{SPECT}$ and/or post-treatment 
${ }^{90}$ Y-PET images $(35,36,49-52)$ identifying the heterogeneity of the activity distribution at the spatial resolution of SPECT or PET. Recent studies have applied the voxel dosimetry to ${ }^{90}$ Y-PET images to obtain dose distribution maps and DVH $(36,37,49,50,53)$. These methods, which recall those used in EBRT, could improve dose-effect correlations and identify appropriate radiobiological models.

\section{ACTIVITY DISTRIBUTION AT THE MICROSCOPIC LEVEL}

The standard dosimetry at the organ level assumes uniform activity in tissues and considers only marginally patient-specific variations. Based on 3D image analysis, the heterogeneity of the activity distribution can be assessed at the spatial resolution of SPECT or PET, which remains, however, at the macroscopic level $(35,36$, 49, 51-54). To assess the heterogeneity at the microscopic level, and more deeply understand the radiobiological mechanisms, some authors analyzed the particle distribution of explanted livers $(55,56)$. Other studies have elaborated mathematical simulations of the hepatic structures to derive the dosimetry at the microscopic scale. This paragraph focuses on the main issues of these studies.

Fox et al. (55) were the first to introduce the basic argument of the non-uniformity of dose distribution at microscopic level, studying the microsphere positions in an explanted treated liver. They found that dose distribution around a microsphere exhibits an extreme dose gradient of more than 5 orders of magnitude in $2 \mathrm{~mm}$ and thus the non-uniformity of dose deposition spares regions of parenchyma, increasing its tolerance with respect to EBRT.

Yorke et al. (57) applied a parallel model introducing a microscopic lobule model to account for non-uniform dose deposition at microscopic level and explain the lack of liver complications with liver absorbed doses up to $150 \mathrm{~Gy}$ (58). Dose-rate effects were also introduced and variable values of the enzymatic halftime of sub-lethal damage repair $\left(T_{\text {rep }}=0.5,1,1.5,2 \mathrm{~h}\right)$ were considered. Interestingly, TD5 and $\mathrm{TD}_{50}$ values increased by more than $50 \mathrm{~Gy}$ compared to the uniform dose distribution, confirming the impact of non-uniformity.

Ten years later, Kennedy et al. (56), provided the pathologic hepatic findings in four explanted livers, performing dosimetry on a microscopic scale in a $T$ irradiated with glass microspheres. The authors found a preferential and heterogeneous deposition of microspheres at the edge of $T$ nodules compared with the center of the tumor or NL, with a ratio from $3: 1$ to $20: 1$. The consequence is a selective radiation delivery to the T/NL edge. Resin and glass microspheres showed similar distribution in NL, whilst a higher number of resin spheres tended to cluster at the edge of the $T$ nodules. This was imputed to different number of resin and glass spheres administered and to higher specific activity of glass spheres. No veno-occlusive disease (VOD) or radiation hepatitis but only slight radiation effect was observed in NL parenchyma far from the tumors (over the range of the $\beta$ particles). 3D dose calculations showed that both glass and resin microspheres deliver heterogeneous absorbed doses to the tumor (ranging from $100 \mathrm{~Gy}$ to more than $3000 \mathrm{~Gy}$ ). A rapid dose falloff from 300 to $100 \mathrm{~Gy}$ within $4 \mathrm{~mm}$ was reported. The two cases of colon metastases showed at least $90 \%$ necrosis in all tumor nodules. Overall, the findings confirmed that both liver tumor (HCC and metastases) are preferentially vascularized by the hepatic artery and that the vasculature is crucial for the efficacy of RE. Vessel density is heterogeneous within the liver and the $T$ (6), as the activity distribution, and therefore less effective than in EBRT.

In the paper by Gulec et al. (1), a 3D hexagonal liver model based on lobular microanatomy was developed, and the microscopic absorbed dose distribution was calculated in various components of the NL structure by Monte Carlo code. Spheres in NL are entrapped within the terminal arterioles/portal tracts at the edges of each lobule, which have diameters comparable to those of the microspheres $(30 \mu \mathrm{m})$. The model represented this pattern considering a hepatic lattice of lobules and the corresponding vascularity, with the portal tract (hepatic artery, portal vein, and bile duct), and the central vein at the center of each lobule. A uniform linear distribution of the microspheres was reproduced within the hepatic artery (no clustering was simulated), with different scenarios including $50 \mathrm{~Bq} / \mathrm{sphere}$ (resin) and $2500 \mathrm{~Bq} /$ sphere (glass). Evaluations according to the macroscopic compartmental model based on MIRD equations were also performed for comparison purposes. The results revealed that average parenchymal and central vein absorbed doses were similar to the average NL absorbed dose of the compartmental model, while the portal tracts received significantly higher absorbed doses. For a single sphere, the central vein received approximately $\sim 6 \%$ of the absorbed dose received by the portal tract, compensated by the cross-fire effect to a fraction of $\sim 50 \%$. The major difference observed between the two types of spheres was that for resin spheres, the absorbed dose to portal tract was more than twofold the absorbed dose to the NL, whilst for glass microspheres, the absorbed dose to portal tract could be slightly lower or more than threefold the liver absorbed dose, with marked non-uniformity in portal tracts for glass spheres. Furthermore, it was shown that a significant cross-fire effect increases the absorbed dose to the hepatocellular parenchyma and the central vein. The authors concluded that there was a consistent relationship between the average liver dose as from MIRD macrodosimetry and the microscopic dosimetry estimates. This study validates the clinical utility of the MIRD methodology in the accurate estimation of the absorbed doses to the central vein and parenchyma, but not to the portal tracts. These results are compatible with REILD, as defined by Sangro et al. $(1,59)$ (see section Side effects to the liver). A strongly non-uniform absorbed dose distribution in portal tracts for glass microspheres is in agreement with the observed higher tolerance.

Another model assessing microscale dosimetry was applied recently by Walrand et al. (60) to explain the apparent paradox of higher liver tolerance to glass (13) as compared to resin spheres (16). Assuming a random microsphere trapping in the portal tracts combined to the different number of spheres, the authors calculated a non-uniform absorbed dose distribution in order to justify the above discrepancies. The same liver model by Gulec et al. (1) was considered, but symmetric and asymmetric branching probabilities of the microspheres were considered at each vessel bifurcation. Simulations were performed leading to absorbed doses of 120 and $40 \mathrm{~Gy}$ to the liver for glass and resin microspheres, respectively. The results showed that for a 60 $40 \%$ branching probability, the fraction of portal tracts without 
trapped glass microsphere increased, and the lobular dose distribution of glass spheres became strongly asymmetric, with a maximum value of $50 \mathrm{~Gy}$ (as compared to $103 \mathrm{~Gy}$ of a symmetric spreading). Most importantly, the dose distribution of the portal triads (the critical tissue in RE) of the glass spheres was similar to that of resin microspheres despite a threefold mean absorbed dose difference to the liver. Therefore, the model justifies that the liver tolerance raises from $40 \mathrm{~Gy}$ for resin spheres to $120 \mathrm{~Gy}$ for glass spheres.

Another interesting point raised by Walrand et al. (60) regards the embolization effect of the portal tracts by the resin microspheres. Without accounting for embolization, a higher number of lobules had at least a portal triad receiving $<40 \mathrm{~Gy}$ as compared to the case in which embolization was considered: the effect was to redirect a part of the resin microspheres to portal tracts of lower initial trapping probability. Embolization reduces the nonuniformity of the resin microsphere distribution among portal tracts and increases the number of portal tracts receiving more than $40 \mathrm{~Gy}$, with a potentially more toxic treatment. In the clinical applications, the role of embolization with resin spheres is still to be clarified, as controversial results have been published, with a trend toward improved OS of patients with the stasis phenomenon (61), in contrast to only mild inflammation of animal tissues embolized with non-radioactive resin microspheres (62).

Comparing clinical findings with the two kinds of devices, Chiesa et al. $(2,12)$ suggested that for a fixed mean absorbed dose, the higher the number of particles/GBq, the higher the biological effect. The study by Walrand et al. microscopically interpreted this phenomenon for normal tissue. The distribution at the microscopic scale varies with the number of particles/GBq, increasing toxicity and efficacy, thus new safe mean absorbed doses should be derived (lower with increasing the number of particles) based on future clinical studies. Lewandowski et al. (63) recently reported a study exploring the possible benefits of a "delayed" (an extended shelf-life) treatment with higher number of glass spheres/Gy. In particular, a time shift providing a double number of glass spheres compared to the reference date was considered, keeping the same standard absorbed dose (123 Gy). The authors hypothesized that increasing the number of glass microspheres, a better tumor distribution would occur without additional adverse events. They concluded that this methodology was safe with promising response rate. However, a better understanding of the potential and risk of this approach needs a more systematic comparison among patients having similar clinical status and pathology. Moreover, tumor and NL averaged absorbed dose should be calculated to better clarify the safety and efficacy. Finally, keeping the same rationale of 120 Gy to the lobe should be regarded with caution, being a sort of absorbed dose-escalation study at the microscopic level (especially to the portal tracts), because a higher NL absorbed dose could overcome the threshold for side effects.

\section{RADIOBIOLOGICAL MODELING}

The linear quadratic model (LQM) has been used to describe the radiobiological effects in several radionuclide therapies and details can be found in reference (11). More relevant definitions also used in EBRT are introduced. The biological effective dose (BED) is widely used to assess the effect of absorbed doses, uniformly delivered in a few minutes in multiple fractions in EBRT. The BED accounts not only for the absorbed dose but also for the dose rate, when assessing the tissue response to the radiation injury. More recently, the LQM has been reformulated to model therapies with continuously variable dose rate, and possibly non-uniform absorbed dose distribution, such as RE. Thus, for two different radiation modalities with the same BED, the same biological effect is expected to occur, provided to be able to evaluate the BED with enough accuracy.

The principal equations of the radiobiological method are here summarized:

$$
\begin{aligned}
\ln (\mathrm{SF}) & =-\alpha \mathrm{BED} \\
\text { for EBRT: } \quad \mathrm{BED} & =D_{\mathrm{EBRT}}\left(1+\frac{D_{\mathrm{EBRT}} / N}{\alpha / \beta}\right) \\
\text { for RE: } \quad \mathrm{BED} & =D_{\mathrm{RE}}\left(1+\frac{D_{\mathrm{RE}} \cdot \lambda_{\mathrm{eff}}}{\left(\mu_{\mathrm{rep}}+\lambda_{\mathrm{eff}}\right) \cdot \alpha / \beta}\right) \\
& \text { or } D_{\mathrm{RE}}\left(1+\frac{D_{\mathrm{RE}} \cdot T_{\mathrm{rep}}}{\left(T_{\mathrm{rep}}+T_{\mathrm{eff}}\right) \cdot \alpha / \beta}\right)
\end{aligned}
$$

where SF is the fraction of cells surviving after irradiation, $\alpha / \beta$ gives the curvature of the survival curve and relates the intrinsic radiosensitivity $\alpha$ and the potential sparing capacity $(\beta)$, $D_{\text {EBRT }}$ is the absorbed dose delivered with EBRT in $N$ fractions (absorbed dose per fraction: $D_{\mathrm{EBRT}} / N$ ), $D_{\mathrm{RE}}$ is the absorbed dose delivered with RE, $\lambda_{\text {eff }}$ is the effective rate constant of a monoexponential variation of the absorbed dose rate, as applies in RE, which accounts for a protracted radiation where repair of sublethal DNA damage can occur (in RE, $\lambda_{\text {eff }}$ equals the physical decay constant of $\left.{ }^{90} \mathrm{Y}: \lambda_{\text {eff }}=\lambda_{\text {phys }}=0.0108 / \mathrm{h}\right), \mu$ is a monoexponential repair constant of a single DNA strand damage, and $T_{\text {eff }}\left(T_{\text {eff }}=T_{\text {phys }}=64.2 \mathrm{~h}\right)$ and $T_{\text {rep }}$ are the halftimes for ${ }^{90} \mathrm{Y}$ decay and repair damage.

The radiobiological parameters included in Eqs 1-3 are specific for the tissues and the effects (typically, $\alpha / \beta$ is assumed to be $2.5 \mathrm{~Gy}$ for the normal tissue and $10 \mathrm{~Gy}$ for the $T$. $T_{\text {rep }}=2.5 \mathrm{~h}$ for $\mathrm{NL}\left(\mu_{\text {rep }}=0.28 / \mathrm{h}\right), 1.5 \mathrm{~h}$ for $\left.T\left(\mu_{\text {rep }}=0.53 / \mathrm{h}\right)\right)$.

In case of spatial absorbed dose non-uniformity, the equivalent uniform BED (EUBED) has been used for $T$ and organs with parallel structure to represent the uniform biological absorbed dose, which would produce the same number of surviving cells (64). It can be calculated to assess the possible radiobiological effect, according to the following equation:

$$
\mathrm{EUBED}=-\frac{1}{\alpha} \ln (\mathrm{SF})=-\frac{1}{\alpha} \ln \left(\int_{0}^{\infty} P(\mathrm{BED}) \cdot e^{-\alpha \cdot \mathrm{BED}} \mathrm{dBED}\right)
$$

where $\mathrm{P}(\mathrm{BED})$ represents the probability density function of $\mathrm{BED}$, and $\exp (-\alpha \mathrm{BED})$ expresses the fraction of surviving cells SF. This applies in case of $T$ or in case of functional subunits of parallel organs, as the liver and the lungs $(10,65)$.

In some cases of RE, also the equivalent uniform dose (EUD) can be a useful parameter. It represents the absorbed dose given 
uniformly that will lead to the same effect as the actual nonuniform absorbed dose distribution, and can be extrapolated by solving the following equation:

$$
\mathrm{EUBED}_{\mathrm{RE}}=\operatorname{EUD}_{\mathrm{RE}}\left(1+\frac{\lambda}{(\mu+\lambda) \cdot \alpha / \beta} \mathrm{EUD}_{\mathrm{RE}}\right)
$$

This equation mirrors Eq 3 but accounts for non-uniformity. Similarly, EUD for EBRT can be derived as the solution of:

$$
\mathrm{EUBED}_{\mathrm{EBRT}}=\operatorname{EUD}_{\mathrm{EBRT}}\left(1+\frac{\mathrm{EUD}_{\mathrm{EBRT}}}{N \cdot \alpha / \beta}\right)
$$

Concerning the risk of toxicity, the phenomenological curves of NTCP (66) derived from the EBRT experience can be considered. The expression proposed to fit the EBRT absorbed dose-response data for a uniform irradiation of the whole organ is:

$$
\begin{aligned}
& \text { NTCP }=\frac{1}{\sqrt{2 \pi}} \int_{-\infty}^{\mathrm{t}} \exp \left(-\frac{x^{2}}{2}\right) d x \\
& \text { with } \quad t=\frac{D-\mathrm{TD}_{50,5}}{m \cdot \mathrm{TD}_{50,5}}
\end{aligned}
$$

where $D$ is the total absorbed dose, $m$ is a parameter representing the steepness of the dose-effect curve, and $\mathrm{TD}_{50,5}$ is the absorbed dose value for which $50 \%$ of the population exhibited complications within 5 years for a uniform whole-organ irradiation.

An alternative definition of EUD was proposed in EBRT. When the organ is irradiated with a non-uniform absorbed dose distribution, with fractions of volumes $v_{\mathrm{i}}$ uniformly irradiated with an absorbed dose $D_{\mathrm{i}}$ (identifying the series $\left\{v_{\mathrm{i}}, D_{\mathrm{i}}\right\}$ ), the effective volume method is applied in EBRT for reducing the DVH data to the unique parameter EUD (67). The NTCP associated to the non-uniform absorbed dose distribution can thus be calculated from Eqs 7 and 8 assuming that the whole organ is uniformly irradiated with an absorbed dose equal to EUD. The parameter EUD is defined as:

$$
\mathrm{EUD}=\left(\sum_{\mathrm{i}} D_{\mathrm{i}}^{\frac{1}{\mathrm{n}}} v_{\mathrm{i}}\right)^{\mathrm{n}}
$$

where $n$ is the volume-effect parameter (e.g., $n=0$ for serial organs, $0<n<1$ for serial-parallel organs).

In order to apply the same model in case of an hypothetical uniform RE irradiation, the BED values from RE need to be converted into the equivalent dose at $2 \mathrm{~Gy} /$ fraction (EQD2), the standard treatment of EBRT, according to Eq 10:

$$
\mathrm{EQD} 2=\frac{\mathrm{BED}_{\mathrm{RE}} \cdot \alpha / \beta}{2+\alpha / \beta}
$$

Similarly, in case of non-uniformity, the $\left\{v_{i}, \mathrm{BED}_{\mathrm{i}}\right\}$ series derived from molecular radio-therapy (MRT) can be converted into a series $\left\{\left(v_{\mathrm{i}}, \mathrm{EQD}_{\mathrm{i}}\right)\right\}$, which are the input for $\mathrm{Eq} 9$ to derive EUD, and then apply Eqs 7 and 8.
As regards $T$, a generalized expression of BED includes the effect of repopulation that occurs during treatment and wasting some of the delivered absorbed dose (68). Considering an exponential clonogen proliferation with doubling time $T_{\mathrm{av}}$ and a time of treatment $T$, the Eq. 3 becomes:

$$
\mathrm{BED}_{\text {tumor }}=D_{\mathrm{RE}}\left(1+\frac{D_{\mathrm{RE}} \cdot T_{\mathrm{rep}}}{\left(T_{\mathrm{rep}}+T_{\mathrm{eff}}\right) \cdot \alpha / \beta}\right)-\frac{\ln 2}{\alpha T_{\mathrm{av}}} T
$$

Finally, for a certain T BED (or EUBED in case of non-uniform absorbed dose distribution), the TCP is defined (69) for an initial number of clonogenic cells $N_{0}$ as:

$$
\mathrm{TCP}=\exp \left(-N_{0} \cdot \mathrm{SF}\right)=\exp \left(-N_{0} \cdot \exp (-\alpha \cdot \mathrm{BED})\right)
$$

\section{COMPARING RE AND EBRT}

Few models of TCP and NTCP have been reported in literature that are able to predict the clinical outcome of EBRT, confirming that a correlation is possible when based on the LQM. Considering the $\mathrm{BED}$ concept as possible rationale for RE planning, the equations of the previous paragraph are the simplest way to convert the absorbed doses from RE to EBRT, and vice versa. Moreover, it is possible to follow the EBRT imprint, comprising DVH, dose-volume reduction, EUBED, and/or EUD evaluations. This conversion could allow to derive estimates of prescribed limits to fulfill in RE based on EBRT studies, such as the effects of single lobe (or segment) versus whole liver irradiation, and the possible consequences of concurrent chemotherapy or re-treatment (15). However, the problem is complex due to the liver structure and the different irradiation conditions. Two different end points are under study, since in EBRT the centrilobular vein is the critical target, while in RE the portal tracts have different irradiation mechanism. Moreover, RE deeply differ if using glass rather than resin microspheres, as described in Section "Side effects to the liver." From this point, the irradiation conditions of resin spheres are more similar to EBRT, resulting in more uniform dose deposition.

A purely mathematical example of tolerance doses derived from EBRT is reported in Table 3 assuming uniform dose distribution to the liver and lungs. This could be taken as starting point for proper phase I absorbed dose-escalation studies, which were never done. The following table was extrapolated using a set of radiobiological parameters taken from EBRT, while this applicability should be experimentally confirmed for RE. It is not directly applicable to glass microspheres. For whole liver irradiation, the same biological effect caused by an absorbed dose of $30 \mathrm{~Gy}\left(\mathrm{TD}_{5 / 5}\right)$ with EBRT could correspond to a BED of $54 \mathrm{~Gy}$ and to an absorbed dose of $35 \mathrm{~Gy}$ uniformly released by resin sphere RE.

A second aspect is that smaller volumes of a "parallel organ" (e.g., liver or lungs) can tolerate higher absorbed doses (volume effect). In fact, Emami et al. (70) derived tolerance values producing a risk of $5 \%$ for partial irradiation of the liver, resulting in 35 and $50 \mathrm{~Gy}$ for an irradiation volume equal to $2 / 3$ and $1 / 3$ of the whole organ, respectively. This suggests that lobar or segmental RE treatments can deliver higher absorbed doses when compared to absorbed doses delivered to the whole liver. Moreover, 
Table 3 | Mathematical example of tolerance doses derived from EBRT assuming a uniform dose distribution to liver and lungs.

\begin{tabular}{|c|c|c|c|c|c|c|c|}
\hline & $\begin{array}{l}\text { Treated } \\
\text { volume }\end{array}$ & $\begin{array}{l}\text { TD }_{5 / 5} \text { (Gy) } \\
\text { EBRT }\end{array}$ & $\begin{array}{l}\text { TD }_{50 / 5}(G y) \\
\text { EBRT }\end{array}$ & $\begin{array}{l}\text { BED }_{5 / 5}(\mathrm{~Gy}) \\
\mathrm{EBRT}=\mathrm{RE}\end{array}$ & $\begin{array}{l}\mathrm{BED}_{50 / 5}(\mathrm{~Gy}) \\
\mathrm{EBRT}=\mathrm{RE}\end{array}$ & $\begin{array}{l}D_{5 / 5}(G y) \\
R E\end{array}$ & $\begin{array}{l}D_{50 / 5}(G y) \\
R E\end{array}$ \\
\hline \multirow[t]{2}{*}{ Liver } & $3 / 3$ & 30 & 40 & 54 & 72 & 35 & 44 \\
\hline & $1 / 3$ & 50 & 55 & 90 & 99 & 51 & 55 \\
\hline Lungs & $3 / 3$ & 17.5 & 24.5 & 29 & 41 & 23 & 30 \\
\hline
\end{tabular}

Liver absorbed doses from EBRT (70) converted to BED (values are the same EBRT and RE) and extrapolated for RE assuming $\alpha / \beta=2.5 G y$ (liver), 3 Gy (lungs), $T_{\text {reo }}=2.5 \mathrm{~h}$.

the lower NL is the volume treated, the higher is the tolerability. According to Dawson et al., irradiating less than 25\% of the liver volume allows whichever dosage (71). This was clinically verified by Rhee et al. in super-selective treatment with glass spheres with a median dose of 348 Gy to liver segment (72). RE with resin spheres involving only the right lobe or the left lobe could be roughly compared to an EBRT irradiation of $2 / 3$ and $1 / 3$ of the whole liver, respectively.

A third issue is represented by the different tolerance according to the basal liver status (liver function). Unfortunately, it is rare that a patient is planned for $\mathrm{RE}$ without previous treatments or underlying disease. Metastatic patients planned for RE usually have already received chemotherapy, while HCC is usually superimposed to liver chyrrosis. Patients naïve to RE or with a better liver status should have a higher tolerability as compared to patients after several chemotherapy treatments or with underlying disease. The EBRT experience shows different NTCP curves according to different basal status (73). This has been observed to apply also to RE clinical experience (59). A more detailed comparison of EBRT data can be found in the review of Chiesa et al. (12). After RE with glass spheres, the same group reported an increased liver decompensation rate according to the worsening of Basal Child (13).

A fourth issue concerns the cases of re-treatment. In EBRT, the cumulative absorbed dose to the well-known limits for toxicity. On the contrary, the literature reports several examples of re-treatment in RE, where dose limits were applied to each single administration, but that were overcome cumulatively. Both producer's indications do not mention the problem of re-treatment, meaning that the same BSA or $120 \mathrm{~Gy}$ prescription could be applied repeatedly. This could explain the toxicity reported by some authors after multiple RE treatments $(53,74)$. The problem of safety re-treatment lacks of specific published data. From the radiobiological point of view, multiple administrations with reduced parenchyma adsorbed dose (e.g., $2 \times 20$ Gy) theoretically result in lower BED, i.e., in lower toxicity, than a higher single dose of $40 \mathrm{~Gy}$ in a single administration (15). This aspect can be explained by using LQM and dose-rate effect, well known in EBRT and in some radionuclide therapies $(10,11)$. The cost-benefit ratio of this argument deserves attention and clinical validation and should consider the life expectancy of patients and the complexity of repeated intra-arterial administrations.

\section{DOSE-EFFECTS CORRELATIONS}

The present section proposes a comprehensive overview of the literature as regards the possible correlations between absorbed doses and radiation-induced effects, on normal tissues and $T$.

\section{SIDE EFFECTS}

The principal risks associated to $\mathrm{RE}$ are due to an excessive irradiation to NL and to an extra-hepatic shunt (observed in a low percentage of patients). If an extra-hepatic shunt exists, relevant toxicities, such as radiation pneumonitis, gastric/duodenal ulceration, and radiation cholecystitis can occur (5). LS is observed especially in HCC patients, who need quantitative evaluation of activity driven to lungs. Gastroduodenal complications occur in less than $5 \%$ of cases and can be prevented by careful evaluation of ${ }^{99 \mathrm{~m}}$ Tc-MAA-SPECT images. A potential risk of red marrow irradiation related to possible free ${ }^{90} \mathrm{Y}$ is due to its natural tropism for the bone. About hematological toxicity, the review of Riaz et al. (5) indicates $\sim 25 \%$ lymphocytes reduction in the majority of treated patients. G3 or G4 lymphopenia was reported by Mazzaferro et al. (75) and by Hilgard et al. (76) in $~ 10 \%$ of HCC patients, but the exact origin is still unclear.

To date, the risk of complications induced by RE is acceptable when patients are adequately selected and the procedure of microsphere injection is carefully operated. Nevertheless, threshold absorbed doses avoiding toxicity are still not definitely identified, being neither dosimetry nor NTCP modeling systematically applied, or properly reported. For instance, the studies on glass spheres have usually provided absorbed dose values averaged on the injected portion of liver (without differentiating between NL and T), losing the information about the actual tolerability of the liver parenchyma and of the irradiation required to control the tumor. Using BSA method with resin spheres, the absorbed doses to NL vary in a wide range [median $36 \mathrm{~Gy}$, range: 6-78 Gy (16)]. Moreover, an average dose that assumes uniform activity does not reflect the actual microsphere distribution (36). These drawbacks have been recently highlighted and works reporting dosimetry information, as well as the quality of dosimetric evaluation, has consistently increased. Studies at the microscopic level have offered complementary information that allow to better interpret the experimental findings $[(1,56,60)$; section Activity Distribution at the Microscopic Level]. 


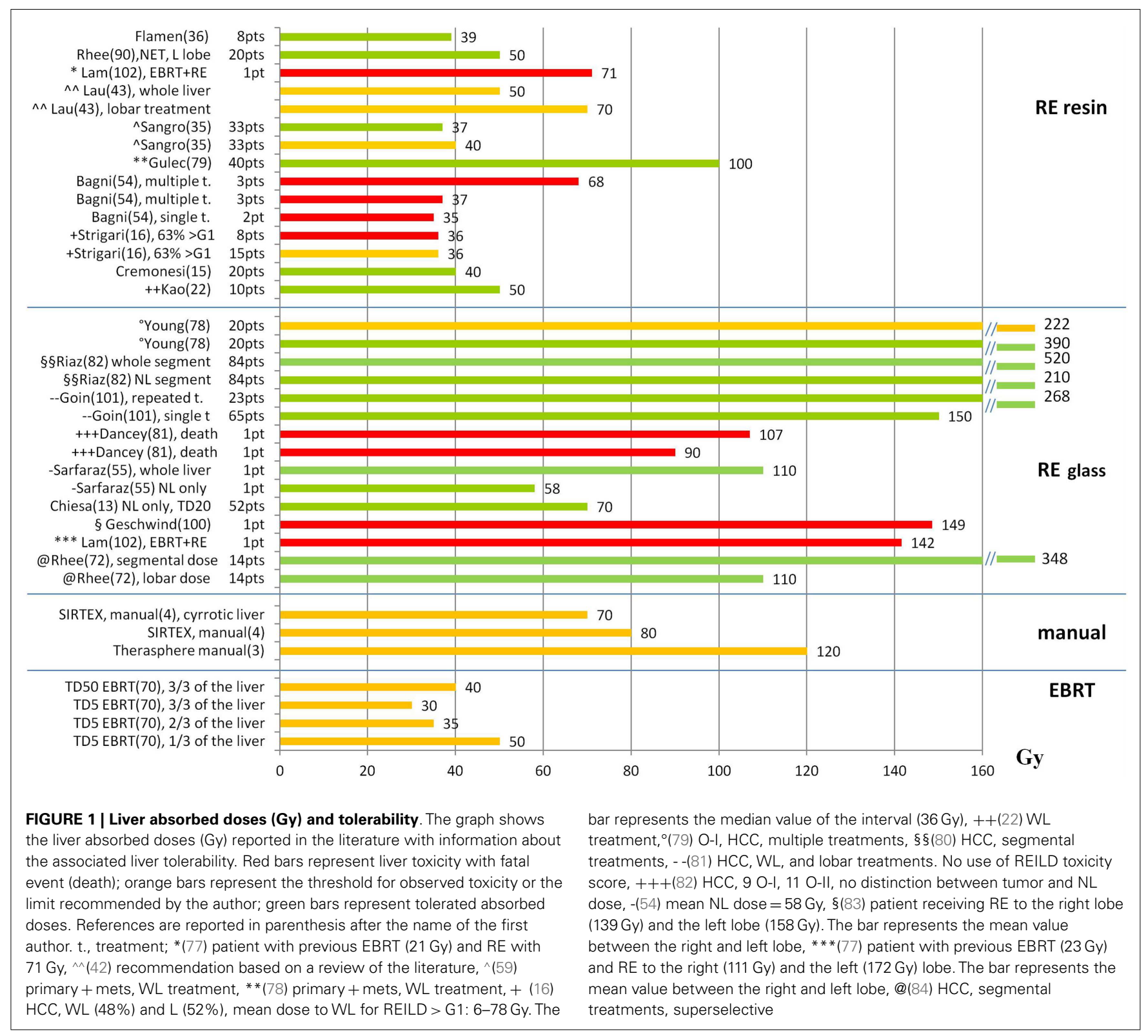

Figures 1 and 2 summarize the correlations between absorbed doses and side effects to the liver and the lungs, highlighting tolerated absorbed doses (green bars), limits for toxicity or recommendations (orange bars), and manifested toxicity (red bars). Table 4 reports the fatal events documented in the literature due to radiation liver toxicity (Table $\mathbf{4 A}$ ) and radiation pneumonitis (Table 4B).

\section{Side effects to the liver}

Some authors have distinguished between the classic radiationinduced liver disease (RILD) associated to EBRT, and the occurrence of REILD (59), the two having different profiles. The manifestation of RILD occurs typically 2-24 weeks after EBRT. It is dominated by vascular injury to the central vein, which is the most radiosensitive tissue in the hepatic microanatomy, characterized by a wall thickening that leads to VOD. There is the development of portal hypertension, ascites, and altered liver function tests, in particular an increase of alkaline phosphatize level, while liver enzymes and total bilirubin level may change only slightly $(85,86)$. Instead, REILD manifests typically within 2 months after RE and can damage mainly the portal tracts. A subacute and chronic portal triaditis could represent the effect of higher absorbed doses in the portal triads. The common clinical effects are ascites, jaundice, total bilirubin increase, increase in alkaline phosphatase and GGT, and splenomegaly at various degrees, which might suggest subclinical or low-grade portal hypertension $(1,12)$. The distinction between RILD (injury to the central vein) and REILD (injury to the portal tracts) compares well with the absorbed dose distribution at the microscopic level derived by mathematical modeling of the microspheres within the vessels $(1,60)$ (see section Activity Distribution at the Microscopic Level). 


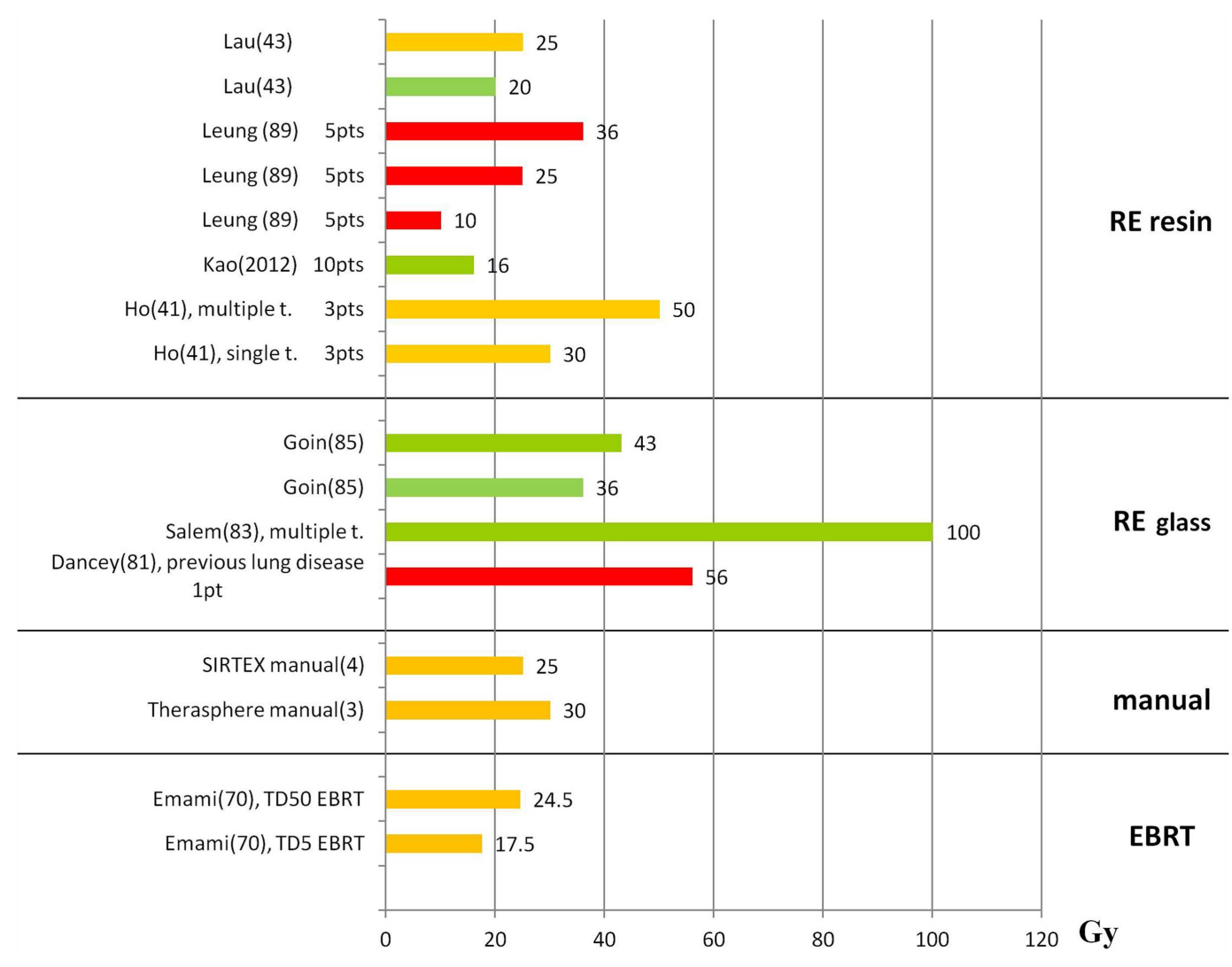

FIGURE 2 | Lung absorbed doses (Gy) and tolerability. The graph shows the lung absorbed doses (Gy) reported in the literature, with information about the associated lung tolerability. The absorbed doses taken from the literature are reported although these are derived without including the attenuation correction. Absorbed dose values should be rescaled by an average factor of 0.6 (12). Red bars represent radiation-induced pneumonitis leading to death; orange bars represent the threshold for observed radiation-induced pneumonitis or the limit recommended by the author; green bars represent tolerated absorbed doses. The references are reported in parenthesis after the name of the first author.
Liver toxicity is evaluated by assessment of enzymes and metabolites, i.e., ALT, AST, alkaline phosphatize, albumin, bilirubin, INR, or clinical symptoms (clinically detectable ascites, bleeding from esophageal varices, and encephalopathy). In patients with HCC, it is difficult to assess whether liver toxicity is due to worsening of hepatic cirrhosis, to disease progression or to RE. Timing is the argument generally adopted to consider a liver adverse event as treatment related or not. Events within 3 or 6 months are usually considered treatment related, depending on the authors. There is a lack of consensus about the exact liver toxicity definition, which encumbers data comparison. Mazzaferro et al. (75) introduced an ad hoc definition of liver decompensation, with a wide acceptance window (a cutoff of 6 months after treatment, including reversible adverse events), while Garin et al. (14) choose a 3 months cutoff, including only irreversible events and excluding cases attributable to $T$ progression or portal vein presence. This resulted, for the same kind of HCC patients treated in the same way, in a liver decompensation incidence of $36.5 \%$ for the first group, while $9.5 \%$ for the second.

When reporting dose-effects to the liver, distinction needs to be made between resin and glass spheres, as absorbed doses values are not directly comparable (Table 2): for resin spheres, the mean absorbed dose to the NL is generally reported, while for the glass spheres the mean absorbed dose to the whole liver or treated lobe is usually expressed. As can be seen from viewing Figures 1 and 2, tolerance levels for glass spheres are higher in terms of grays.

Liver toxicity after resin spheres. Kennedy et al. (24) presented the results of 680 treatments on 515 patients. The median prescribed activities were $2.0 \pm 0.4 \mathrm{GBq}$ (empirical method), $1.6 \pm 0.5 \mathrm{GBq}$ (BSA method), and $1.1 \pm 0.6 \mathrm{GBq}$ (actually delivered). REILD occurred in 28 treatments $(4 \%)$ and lead to death. Of these, in 21 of a single center, the activity to be administered was decided by the empiric method, and 20 were a bilobar approach. Unfortunately, the absorbed doses to NL are not available. According to the authors, REILD significantly correlated with the administered activity, thus indirectly with the liver absorbed dose. The high risk of death with method (i) lead to the recommendation to avoid the empirical method and whole liver treatments (5).

Sangro et al. (59) observed an increased toxicity in patients receiving an absorbed dose to NL of $37 \pm 12$ Gy versus $26 \pm 12 \mathrm{~Gy}$ ( ${ }^{99 \mathrm{~m}}$ Tc-MAA, partition model) (Figure 1). VOD was observed only in patients who received chemotherapy. The incidence of 
Table 4 | (A) Fatal events due to liver failure; (B) Fatal events due to radiation pneumonitis.

\begin{tabular}{|c|c|c|c|c|c|}
\hline Reference & $\begin{array}{l}\text { Type of } \\
\text { spheres }\end{array}$ & $\begin{array}{l}\text { Method for activity } \\
\text { determination }\end{array}$ & $\begin{array}{l}\text { No. of patients with } \\
\text { adverse events } \\
\text { leading to death }\end{array}$ & $\begin{array}{l}\text { HCC or } \\
\text { metastases }\end{array}$ & Notes \\
\hline \multicolumn{6}{|l|}{ (A) } \\
\hline Lau et al. (102) & Resin & Empirical & $4 \%(3 / 71)$ & $\mathrm{HCC}$ & Liver failure but not RILD \\
\hline Geschwind et al. (83) & Glass & $\begin{array}{l}100 \text { Gy to whole liver; } \\
135-150 \text { Gy to whole liver }\end{array}$ & $1 \%(1 / 80)$ & $\mathrm{HCC}$ & $139 \mathrm{~Gy}$ to right lobe; $158 \mathrm{~Gy}$ left lobe \\
\hline Goin et al. (81) & Glass & $\begin{array}{l}50-150 \text { Gy to the whole } \\
\text { liver or the lobe treated }\end{array}$ & $5 \%(6 / 121)$ & $\mathrm{HCC}$ & In practice: 130 (34-268) Gy \\
\hline Dancey et al. (82) & Glass & 100 Gy to whole liver & $9 \%(2 / 22)$ & $\mathrm{HCC}$ & $\begin{array}{l}\text { Absorbed doses of } 90 \text { and } 107 \mathrm{~Gy} \text {; whole } \\
\text { liver treatment (range given: } 46-145 \mathrm{~Gy} \text { ) }\end{array}$ \\
\hline Sangro et al. (101) & Resin & $\mathrm{BSA} ;<60$ Gy to $\mathrm{NL}$ & $8 \%(2 / 24)$ & $\mathrm{HCC}$ & $53 \mathrm{~Gy}(2.43 \mathrm{GBq})$ and $46 \mathrm{~Gy}(2.04 \mathrm{GBq})$ \\
\hline Kennedy et al. (24) & Resin & $\begin{array}{l}\text { empirical } \\
\text { BSA }\end{array}$ & $\begin{array}{l}4.1 \%(28 / 515) \\
1.5 \%(7 / 515)\end{array}$ & $\begin{array}{l}\mathrm{HCC} \text { and } \\
\text { metastasis }\end{array}$ & In the same center using the Empirical \\
\hline Strigari et al. (16) & Resin & BSA & $11 \%(8 / 73)$ & $\mathrm{HCC}$ & (plus $15 / 73$ pts with hepatic coma) \\
\hline Bagni et al. (53) & Resin & $\begin{array}{l}\text { BSA }(1.6,1.68,1.3+1.3 \\
1.85+1.5,1.85+1.5 \mathrm{GBq})\end{array}$ & $4 \%(5 / 135)$ & Metastasis & $\begin{array}{l}\text { Mean absorbed dose to the liver: } 35,38 \text { Gy } \\
\text { (single treatment); 37-68 Gy cumulative }\end{array}$ \\
\hline Lam et al. (77) & $\begin{array}{l}\text { Resin } \\
\text { Glass }\end{array}$ & $\begin{array}{l}\mathrm{BSA}(1.5 \mathrm{GBq}) \\
120 \mathrm{~Gy} \text { to the treated liver } \\
(7.3 \mathrm{GBq})\end{array}$ & $\begin{array}{l}3 \%(1 / 31) \\
3 \%(1 / 31)\end{array}$ & $\begin{array}{l}\text { Metastasis } \\
\text { HCC }\end{array}$ & $\begin{array}{l}21 \mathrm{~Gy} \text { from EBRT and } 71 \mathrm{~Gy} \text { from RE } \\
23 \mathrm{~Gy} \text { from EBRT and } 172 \mathrm{~Gy} \text { (left } \\
\text { lobe) }+111 \mathrm{~Gy} \text { (right lobe) from RE }\end{array}$ \\
\hline \multicolumn{6}{|l|}{ (B) } \\
\hline Leung (89) & $\begin{array}{l}\text { Not } \\
\text { specified }\end{array}$ & Not specified & $3 / 80$ pts & $\mathrm{HCC}$ & $\begin{array}{l}\text { LS within } 13-46 \% \text {, absorbed doses } 10,25 \text {, } \\
\text { and } 25 \text { Gy without attenuation correction, } \\
\text { corresponding to } \sim 6,15 \text {, and } 15 \text { Gy with } \\
\text { attenuation correction }\end{array}$ \\
\hline Dancey (82) & Glass & $\begin{array}{l}100 \mathrm{~Gy} \text { to the whole liver } \\
(\mathrm{NL}+\mathrm{T})\end{array}$ & $1 / 22$ pts & $\mathrm{HCC}$ & $\begin{array}{l}\text { LSF 39\%; absorbed dose of } 56 \text { Gy without } \\
\text { attenuation correction, corresponding to } \\
\sim 34 \text { Gy with attenuation correction; previous } \\
\text { lung chronic disease and lung embolism }\end{array}$ \\
\hline
\end{tabular}

The absorbed doses values in the "Notes" column report the specific values given to patients who manifested a fatal event.

REILD was associated with young age ( $<55$ years), diffuse disease, bilobar treatment, previous chemotherapy and/or pre-existing altered liver function, bilirubin level, and administered activity. The results indicated as threshold for REILD the mean absorbed dose of 40 Gy to NL.

The use of the LQM model as rationale of RE was proposed by Cremonesi et al. (15), who applied the limit of 40 Gy to NL in 20 patients with liver metastasis treated with total liver approach. The threshold value was extrapolated from the $\mathrm{TD}_{5,5}$ of EBRT, with proper conversion to RE by the BED concept, using a limit of $35 \mathrm{~Gy}$ $\left(\mathrm{BED}=54 \mathrm{~Gy}, \mathrm{EQ} 2=\mathrm{TD}_{5,5}=30 \mathrm{~Gy}\right)$ in a few patients, followed by an absorbed dose escalation to $40 \mathrm{~Gy}(\mathrm{BED}=64 \mathrm{~Gy})$. No toxicity was observed apart from transient elevation of liver enzymes. The authors suggested the use of the LQM also as theoretical basis to evaluate the risk/benefit balance of re-treatment or bilobar approaches, which are empirically applied instead $(72,79,80,86)$.

Out for 135 patients, Bagni et al. (53) reported 5 cases (4\%) of liver failure that led to death 3-4 months after RE. The activity ranged from 1.3 to $1.85 \mathrm{GBq}$ (BSA method). Simulation with ${ }^{99 \mathrm{~m}}$ Tc-MAA was not performed, but post-therapeutical ${ }^{90} \mathrm{Y}$-PET images showed diffused radioactivity in the liver and reduced tumor uptake. Voxel dosimetry was performed. Two patients received a single treatment with mean absorbed doses to NL of $34.5 \mathrm{~Gy}(\mathrm{EQ} 2=30 \mathrm{~Gy}, \mathrm{BED}=54 \mathrm{~Gy})$ and $38.5 \mathrm{~Gy}(\mathrm{EQD} 2=33 \mathrm{~Gy}$, $\mathrm{BED}=61 \mathrm{~Gy}$ ) assuming $\alpha / \beta=2.5 \mathrm{~Gy}$. The other three patients underwent two treatments with cumulative mean absorbed doses ranging from 37 to $68 \mathrm{~Gy}$ (EQD2: 31.8-76.5 Gy, BED: 57.3137.7 Gy). Details about the clinical status of the patients were not reported, but the absorbed doses received also in the first treatment adhere to the limits extrapolated from EBRT. These cases with resin spheres showing - at least from imaging - nearly uniform irradiation of NL, are more closely reproducing the uniform irradiation of EBRT.

Strigari et al. (16) applied to a nuclear medicine treatment the radiobiological methods used in EBRT, pointing to the methodology that should be used to describe the effects and to plan any radiation treatment nowadays. The authors analyzed 73 HCC patients Voxel dosimetry was retrospectively assessed from Bremsstrahlung images. They found that the mean absorbed dose was a predictor for liver failure and a modified Lyman-BurmanKutcher model was applied to obtain a fitted NTCP curve with toxicity $>$ G1 as end-point. The parameters describing the NTCP 
were a $\mathrm{TD}_{50}$ of $52 \mathrm{~Gy}(95 \% \mathrm{CI}, 44-61 \mathrm{~Gy})$ and a slope of NTCP versus dose of $0.28 \mathrm{~Gy}^{-1}$ (95\%CI, 0.18-0.60), assuming $n=1$.

Di Dia et al. (51) applied the voxel dosimetry method to ${ }^{99 \mathrm{~m}} \mathrm{Tc}$ MAA-SPECT images of 13 metastatic patients undergoing whole $\mathrm{RE}$ with resin spheres, with a prescribed mean absorbed dose of $40 \mathrm{~Gy}$ to NL (assuming an uniform distribution). No toxicity was observed, as expected. In principle, higher activities could have been administered according to the degree of non-uniformity highlighted by the voxel dosimetry. Average doses, BED, EUBED, and EUD, were calculated for several $\alpha$ and $\alpha / \beta$ values. EUD was considered as possible new constraint, in place of the mean absorbed dose. However, it was found that EUD is notably influenced by the value of $\alpha$. The authors conclude that the $\alpha$ parameter needs to be identified for NL and the specific tumors in order to apply radiobiological quantities for RE protocols.

Lau et al. integrated the clinical experience from literature in a review to guide patient selection and activity planning for RE with resin microspheres (42). In order to minimize fatal events, the authors recommend $50 \mathrm{~Gy}$ as maximum limit in whole treatments and $70 \mathrm{~Gy}$ to the NL lobe treated in lobar approach. Kao et al. (22) did not find toxicity fulfilling these constraints.

Petitguillaume et al. (87) applied for the first time direct Personalized Monte Carlo Dosimetry (PMCD) to resin sphere treatment. CT images created patient-specific voxel phantoms using the OEDIPE software. ${ }^{99 \mathrm{~m}}$ Tc-MAA SPECT images of 10 patients were combined to calculate absorbed dose at voxel level with MCNPX Monte Carlo code. Activity prescription from PMCD and partition model were compared, with or without including DVH criteria. The use of PMCD resulted in higher administrable activity than the partition model calculation. The allowed increase is on the average of $27 \%$ if mean dose constraints are considered, and of $40 \%$ if DVH criteria are adopted.

Liver toxicity after glass spheres. Dancey et al. (82) treated 22 HCC patients (9 Okuda stage I, and 11 Okuda stage II) in a whole liver approach. The median (range) absorbed dose to the whole liver was 104 (46-145) Gy, and to the lungs was 13.0 (1.8-56.5) Gy [with LF: $6.4(1-39 \%)$ ]. Two patients were treated a second time, resulting in total liver doses of 100 and 209 Gy and lung doses of 43 and $36 \mathrm{~Gy}$, respectively. Serious adverse events (severe, life threatening, and death) occurred in 14 patients (63\%), including three deaths. The authors admit that the lack of detailed liver dosimetry with distinction between $T$ and NT parenchyma is a major limitation of their study.

Sarfaraz et al. (54) first investigated the voxel activity distribution in one treated patient. The absorbed dose distribution was retrospectively analyzed by ${ }^{99 \mathrm{~m}} \mathrm{Tc}-\mathrm{MAA}-\mathrm{SPECT}$ images, with isodose curves and DVHs derived for $T$ and liver. The mean $T$ and NL doses were 163 and $58 \mathrm{~Gy}$. No radiation hepatitis was reported for this patient, in agreement with the reduced amount of liver irradiated with more than $110 \mathrm{~Gy}$ and with the use of glass spheres, $58 \mathrm{~Gy}$ is in fact much higher than the tolerance observed in resin spheres and in EBRT.

Goin et al. (81) analyzed a group of 88 patients affected by HCC. The results indicated that pre-treatment bilirubin and liver absorbed dose were the most statistically significant factors associated with an increased risk of liver toxicity. A limit of $150 \mathrm{~Gy}$ for a single administration and of $268 \mathrm{~Gy}$ for a repeated RE were considered as tolerated and reversible. The authors concluded that no cases of serious RILD occurred, being the bilirubin increase, and not the alkaline phosphatase, the mark accompanying ascites in $33 \%$ of patients. However, they did not consider the definition of REILD that possibly occurred.

Rhee et al. $(72,84)$ used CT angiography (CTA) in 14 patients with unresectable HCC to super-selectively administer in liver segments and to evaluate tumor absorbed doses. Activity was planned in order to deliver $120 \mathrm{~Gy}$ to the target lobe. Estimated absorbed doses to the lobe (before CTA) ( $100 \pm 43 \mathrm{~Gy}$, range: 35-169 Gy) were significantly lower than the actual absorbed doses to the target segmental liver volume (after CTA) retrospectively calculated ( $348 \pm 204 \mathrm{~Gy}$, range: $105-857 \mathrm{~Gy})$. Changes in serum bilirubin level were statistically significant within normal levels and were not clinically relevant. Thirteen of 14 patients had no change in Child-Pugh class. This study supports that irradiation of a small organ fraction gives very limited toxicity, enhancing that the well-known liver volume effect in EBRT also applies in RE (see also section Comparing RE and EBRT).

The relationship between cumulative lobar radiation dose and liver toxicities in case of multiple RE procedures has been investigated by Young et al. (79). Forty-one patients affected by HCC and classified according to the Okuda stage I (O-I, 20 patients) and stage II [(O-II), 21 patients] disease were enrolled. The OI group received more treatments than the O-II group, and a higher cumulative absorbed dose to the lobes, with average (range) 247 (88-482) Gy versus 198 (51-361) Gy. Toxicity was observed in only $16 \%$ of patients. O-I patients received a greater cumulative dose than O-II patients before liver function alteration: 390 versus $196 \mathrm{~Gy}$, confirming different tolerance for different initial conditions (section Comparing RE and EBRT). For O-I patients, a higher cumulative absorbed dose was associated with occurrence of one or more toxicities: $222 \mathrm{~Gy}$ (no toxicities) versus $390 \mathrm{~Gy}(\geq 1$ toxicity), confirming that liver toxicities increase with increasing cumulative radiation dose. It is worthy to note that the O-I group manifesting greater tolerability received the cumulative therapy in a higher number of treatments (2.65 versus 2.24 treatments in average), possibly shifting the tolerance toward higher absorbed dose values (see also section Comparing RE and EBRT).

Riaz et al. (80) further applied the segmental RE approach to 84 selected HCC patients. Activity was planned to deliver an absorbed dose of 120 Gy to the lobe. The segment absorbed dose was estimated with the hypothesis of uniform activity, but also with a revised method based on the iodinated contrast medium distribution (subjective assessed by the radiologist), in the attempt to assess a T/NL ratio. The median dose to the segment was $521 \mathrm{~Gy}$ (95\%CI: 404-645 Gy) by the usual method, while it was $210 \mathrm{~Gy}$ (95\%CI: 107-270 Gy) with the revised method. The results highlighted that the T/NL uptake ratio has a great impact on evaluation, remarking the importance of separate $T$ and NL dosimetric evaluation. G3 and G4 toxicity rate was extremely low, confirming the volume effect in RE (see also section Comparing RE and EBRT).

Chiesa et al. (13) retrospectively evaluated on ${ }^{99 m}$ Tc-MAA SPECT images the $T$ and NL absorbed doses of 52 HCC patients lobarly injected according to the prescription of $120 \mathrm{~Gy}$ (75). Liver 


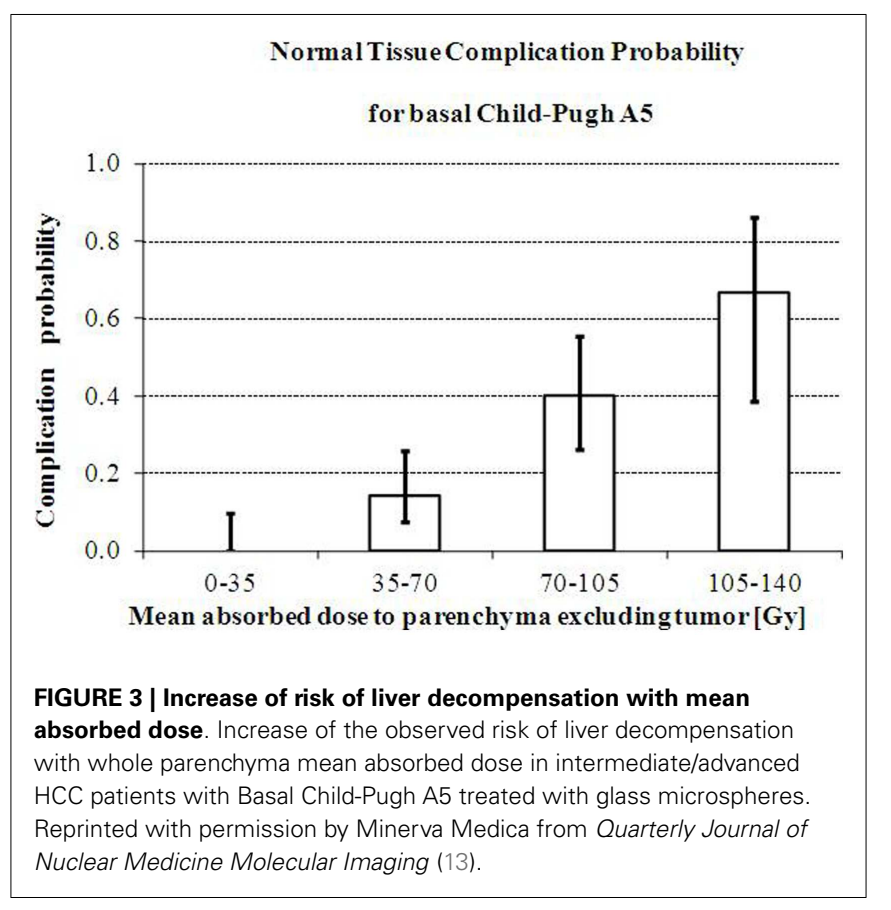

decompensation was defined according to Mazzaferro et al. (75). Basal Child-Pugh strongly affected the toxicity incidence: $22 \%$ for A5, 57\% for A6, and 89\% for B7 patients (univariate analysis). In Child-Pugh A5 patients, absorbed dose averaged on NL was $90 \mathrm{~Gy}$ (liver decompensation) versus $58 \mathrm{~Gy}$ (non-toxic treatments). The experimental NTCP histogram as a function of NL mean-absorbed dose is shown in Figure 3. A limit of about $70 \mathrm{~Gy}$ for the mean absorbed dose to parenchyma can be assumed for Child A5 patients treatment planning, corresponding to a $14 \%$ risk of liver decompensation. This result is applicable only with glass spheres decay interval of 3.75 days.

\section{Side effects to the lungs}

Significant shunting to the lungs is rather rare and avoidable by appropriate patient exclusion criteria. It can lead to progressive pulmonary insufficiency, with pulmonary fibrosis, and ultimately radiation pneumonitis (88). Some authors report the acceptable limit by means of LS percentage, others report the LS and absorbed dose limits. Of relevance, the lung absorbed dose evaluations that are reported in this paragraph and in Figure $\mathbf{2}$ are overestimated, because authors usually do not apply the attenuation correction. The proper values - also for possible comparison with EBRT - should be rescaled by an average factor of 0.6 (12). E.g., the limits of 30 and $50 \mathrm{~Gy}(40,89)$ obtained with resin spheres from non-attenuation corrected images, should be actually 18 and $30 \mathrm{~Gy}$, much closer to the TD values from EBRT $\left(\mathrm{TD}_{5}=17.5 \mathrm{~Gy}\right.$; $\left.\mathrm{TD}_{50,5}=24.5 \mathrm{~Gy}\right)(70)$.

Resin spheres. Leung et al. (89) described 5/80 cases of radiation pneumonitis, with 3 patients who died from respiratory failure. The LS of these patients ranged from 13 to $46 \%$, with associated absorbed doses from 10 to $36 \mathrm{~Gy}$. Recommendations of LS $<13 \%$ (corresponding to $19 \mathrm{~Gy}$ for $3 \mathrm{GBq}$ of microspheres injected) were given, as $55 \%$ of the patients having this LS developed toxicity, which was absent in patients with LS $<13 \%$. Furthermore, 19 Gy was indicated as the lower value to cause radiation pneumonitis.

From the same group, Ho et al. (40) suggested a LS of $20 \%$ and an absorbed dose of $30 \mathrm{~Gy}$ as limits for risk of radiation pneumonitis in a single treatment, and a cumulative absorbed dose of 50 Gy not to be exceeded in repeated treatments.

In a recent paper regarding resin spheres, Lau et al. (42) recommended that lung dose remains $<20 \mathrm{~Gy}$, and never exceeds $25 \mathrm{~Gy}$ (a more cautious approach than 30-50 Gy limits or LS < 15-30\%).

Kao et al. (22) did not find any significant toxicity in 10 patients receiving mean lung absorbed doses lower than $16 \mathrm{~Gy}$.

Glass spheres. Dancey et al. (82) report the death of one patient for radiation-induced pneumonitis ( 6 weeks after RE), with a LS of $39 \%$ and a lung absorbed dose of 56 Gy. In this single case of death from radiation-induced pneumonitis, the patient had a chronic lung disease, and a pulmonary embolism occurred 4 weeks before $\mathrm{RE}$. Instead two patients who received a dose to the lungs $>30 \mathrm{~Gy}$ ( 36 and $43 \mathrm{~Gy}$ ) did not develop any serious adverse pulmonary events (86).

In the study by Salem et al. (88), 58 patients who underwent $\mathrm{RE}$ received a lung absorbed dose $>30 \mathrm{~Gy}$ in single treatment and 50 Gy cumulatively without developing radiation pneumonia. Only 10/53 patients exhibited G1 lung toxicity. Absorbed doses to the lungs higher than 100 Gy were tolerated without any adverse effect. The authors conclude that the most applied limits (30 Gy single, 50 Gy multiple), should be revised and that the model - based on simulation by MAA, assuming uniform activity distribution in the lungs, with same limits for resin and glass microspheres - might not be adequate.

Literature on EBRT has shown that the incidence of radiation pneumonitis better correlates with the volume receiving a certain absorbed dose (e.g., V20 or V30 as lung volume receiving at least 20 or $30 \mathrm{~Gy}$ ) rather than the mean lung absorbed dose (90-92). A better comparison with the EBRT models would require an accurate evaluation of the activity biodistribution in the lung vasculature, incorporating the possible differences of resin and glass microspheres. The microspheres distribution in the lungs is probably uneven, with a preferential distribution to the lung bases and central parts, while a fraction is totally spared $(7,8)$. This may happen because the distribution is affected by gravity and by the blood flow (7). Moreover, the different number of particles could lead to a greater micro-embolic effect with resin as compared with glass microspheres also in the lungs $(88,89)$.

\section{TUMOR RESPONSE}

As point of attention in reviewing published data is that different methods for tumor response evaluation have been considered, based on CT (RECIST, dimensional criteria), EASL (density), or PET parameters (e.g., SUV variation or total lesion glycolysis (TLG), defined as product of the mean lesion SUV and the volume of each lesion). The results available in the literature are summarized in Figure 4, where distinction is made among absorbed doses that are associated to response (green bars), thresholds for response (orange bars) and $\mathrm{T}$ progression (red bars). Blue bars specifically indicate PR (partial response) or SD (stable disease). 


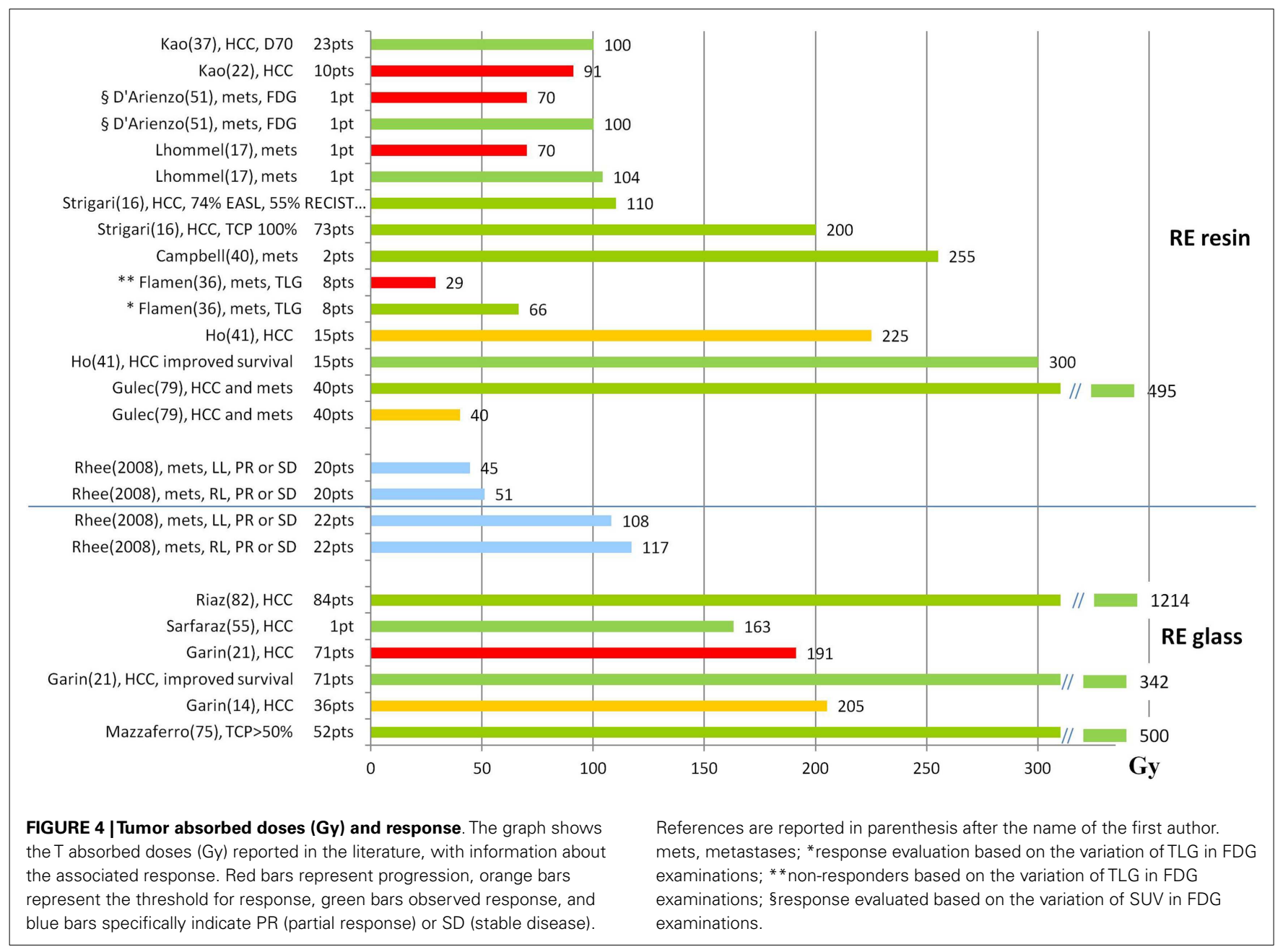

\section{Resin spheres}

Rhee et al. (84) evaluated the response of 42 patients who underwent RE using glass and resin microspheres. In all cases, the lobe but not the NL absorbed dose was evaluated. Using glass, a higher median absorbed dose was delivered to each lobe (right lobe $117 \mathrm{~Gy}$, left lobe $108 \mathrm{~Gy}$ ) than using resin (right $50.8 \mathrm{~Gy}$, left $44.5 \mathrm{~Gy}$ ). According to RECIST criteria, the 6-month disease control rate was similar with both microspheres ( $92 \%$ with glass and $94 \%$ with resin particles). This study gave the same clinical efficacy from different median absorbed doses, as a consequence of different number of microsphere per Gy and different non-uniformity of dose deposition on microscopic scale, as a consequence of different number of microsphere per Gy and different non-uniformity of dose deposition on microscopic scale.

Ho et al. (40) estimated the correlation between tumor absorbed doses and responses in a group of 71 patients affected by HCC. Repeated (two to five) treatments were given to 15 patients. Tumor doses were estimated by the partition model. The median absorbed dose at the first treatment was $225 \mathrm{~Gy}$ (range: 38 $748 \mathrm{~Gy}$ ), while cumulatively was $302 \mathrm{~Gy}$ (range: $83-1580$ ). $37 \%$ of the patients showed a partial response at absorbed doses $>225 \mathrm{~Gy}$, in comparison with $10 \%$ at absorbed doses $<225 \mathrm{~Gy}$. For survival, with a cut-off value of $300 \mathrm{~Gy}$, the median OS of 11 and 7 months was observed in patients above and below the cutoff, respectively, although the difference was not statistically significant.

Flamen et al. (35) made a retrospective dosimetry on ${ }^{99 \mathrm{~m}} \mathrm{Tc}-$ MAA-SPECT images of the PET response in 39 metastatic liver lesions from colorectal cancer in a group of 8 patients treated according to the BSA method (mean; range): $1.69 \mathrm{GBq} ; 1.33-$ $2.04 \mathrm{GBq}$. The paper reports the absorbed doses of the lesions as a function of TLG variation (Figure 5), showing a clear trend, and a correlation coefficient of $R^{2}=0.26$. This apparently low value is similar to others found in nuclear medicine dosimetry (93), and also in EBRT and might be attributed both to the mislocation of points on the abscissa (dosimetric inaccuracy) and in the ordinates (interpatient variability). Different response for the same dose may also be deeply influenced by the lesion dimension. The median (95\% CI) absorbed dose was 29 (1-98) Gy and $66(32-159) \mathrm{Gy}$ in the poor $(<50 \%$ TLG change) and the good responders (TLG change $>50 \%$ ), respectively. From MAASPECT images using T/NL ratio of 1 as cut-off, a significant metabolic response was predicted with a sensitivity of $89 \%$, a specificity of $65 \%$, a positive predictive value of $71 \%$, and a negative predictive value of $87 \%$. Authors concluded that simulation 


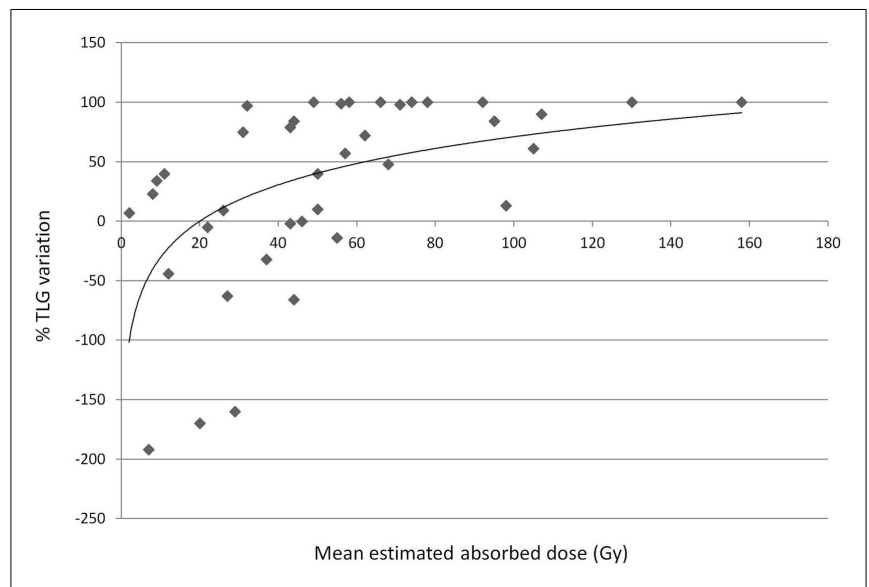

FIGURE 5 |Tumor response related to variation of the TLG with absorbed doses (Gy). $T$ response by means of the TLG variation in FDG-PET examinations versus $T$ absorbed dose. Regression analysis $\left(R^{2}=0.26\right)$. Errata corrige of previously published data by Flamen et al. (35). Data provided by the authors, personal communication.

with MAA can provide essential information for patients' recruitment to RE, allowing to predict the metabolic response. The mean absorbed dose of the normal liver parenchyma was $39 \mathrm{~Gy}$ (32-48 Gy), without toxicity.

Campbell et al. (39) retrospectively analyzed 14 patients affected by metastases from colorectal cancer. The partition model was applied with a $T$ to NL ratio arbitrary of $3: 1$ and a patientspecific ratio ( ${ }^{99 \mathrm{~m}} \mathrm{Tc}$-MAA SPECT images). The response rate was evaluated comparing FDG-PET at baseline and 3 months after RE. There was a statistically different absorbed dose between the two methods. PET showed a mean decrease of $52 \%$ of total SUV in tumors. There was a linear correlation between absorbed dose and tumor response, but the tumor absorbed dose using a patient-specific method was more predictive $(R=0.65)$. Two good responses were observed at 255 and $317 \mathrm{~Gy}$, for lesions of 5 and $13 \mathrm{~g}$.

Strigari et al. (16) implemented a TCP model in RE analyzing the outcome of 73 HCC patients. Response was defined according to the RECIST and EASL criteria (94-96). The radiobiological parameters used to compute BED for HCC were $\alpha / \beta=10$ and $T_{\text {rep }}=1.5 \mathrm{~h}$. Experimental TCP was fitted with the hypothesis of two different cellular radiosensitivity in $T$, obtaining two $\alpha$-values ( 0.001 and $0.05 \mathrm{~Gy})$. Note that these values are definitively lower than those obtained in EBRT ( $\alpha=0.01 \pm 0.1 / \mathrm{Gy}$ ) reported by Tai et al. (97) after in vivo EBRT. TCP curve indicated that all tumors with mean dose greater than $200 \mathrm{~Gy}$ showed a complete or partial response. At lower doses, a higher response rate was found using EASL rather than RECIST criteria, i.e., ${ }^{90} \mathrm{Y}$ irradiation causes changing in $T$ structure rather than its shrinking. With an average dose of 110 Gy to the tumor, complete or partial response was observed in 74 and $55 \%$ of patients according to the EASL and RECIST criteria, respectively.

The paper by Lhommel et al. (17) describes the new method for ${ }^{90} \mathrm{Y}-\mathrm{PET}$ imaging using the low branch of $e$ - $/ e+$ pair production in the ${ }^{90} \mathrm{Y}$ decay (probability: $32 \times 10^{-6}$ ) and a TOF scanner. The authors demonstrated that PET-based microsphere dosimetry is feasible and quantitatively accurate, and they applied the method in a patient treated with resin spheres. The absorbed dose distribution well correlated with tumor control, with good response in regions of high absorbed dose (average absorbed dose $104 \mathrm{~Gy}$, maximum $241 \mathrm{~Gy}$ ), and tumor progression in regions only partially targeted (average absorbed dose $29 \mathrm{~Gy}$, maximum 70.6 Gy). The advantage of this post-therapy technique is the possibility to study the correlation based on the actual absorbed dose, i.e., bypassing the problem of correspondence between ${ }^{99 m}$ Tc-MAA and microspheres, joined with the better PET spatial resolution with respect to SPECT. It is not useful however, to provide a treatment planning tool.

D'Arienzo et al. obtained high resolution post-RE ${ }^{90} \mathrm{Y}$ images by a non-TOF PET/CT scanner provided with bismuth germanate (BGO) crystals $(49,50)$. The voxel dosimetry method was applied for the analysis of a patient with liver metastases, administered according to the BSA method (1.45 GBq) (50). The absorbed dose distribution map and DVHs for both $T$ and NL, showed a wide heterogeneity. The mean absorbed dose to $T$ was $139 \mathrm{~Gy}$, but two areas were distinguished: a hot margin receiving an average absorbed dose of 287 Gy (range: 100-700 Gy) and a cold area with a necrotic core receiving an average absorbed dose of $70 \mathrm{~Gy}$ with a large proportion of voxels receiving $<50 \mathrm{~Gy}$. At the FDGPET control 6 months after RE, complete remission was observed in highly irradiated $T$ areas, while progression was observed in the scarcely irradiated area, demonstrating correlation between absorbed dose and $T$ response, and the role of non-uniformity of dose deposition. The authors conclude that an average radiation dose > 100 Gy may sterilize liver metastases.

Kao et al. (22) highlighted the power of predictive dosimetry in a study involving 10 patients with HCC and very different baseline disease characteristics. The authors introduce the "planning target volume" concept, adapted from EBRT, and state that "despite its popularity, the BSA method has a questionable radiobiological basis and is scientifically inferior to MIRD methodology." The patients were therefore administered with resin microsphere using an artery-specific ${ }^{99 \mathrm{~m}} \mathrm{Tc}$-MAA-SPECT/CT partition model. Median predicted absorbed doses were $106 \mathrm{~Gy}$ (95\% CI, $105 \pm 146 \mathrm{~Gy}$ ) to $T, 27 \mathrm{~Gy}(95 \% \mathrm{CI}, 22 \pm 33 \mathrm{~Gy})$ to $\mathrm{NL}$, and $2 \mathrm{~Gy}$ ( $95 \% \mathrm{CI}, 1.3 \pm 7.3 \mathrm{~Gy}$ ) to lungs. The results showed that a $100 \% \mathrm{~T}$ response rate could be achieved with an absorbed dose of at least $91 \mathrm{~Gy}$.

The same author (36) presented a study of 23 patients affected by HCC and metastases treated with activities based on predictive dosimetry as above. ${ }^{90} \mathrm{Y}$-PET images were acquired after RE and absorbed dose distributions obtained by voxel dosimetry. Dose-responses in tumor was analyzed considering the DVHs $\left({ }^{90} \mathrm{Y}-\mathrm{PET}\right)$ or the mean absorbed doses $\left({ }^{99 \mathrm{~m}} \mathrm{Tc}-\mathrm{MAA}-\mathrm{SPECT}\right)$ in correlation with follow-up imaging or clinical findings $(98,99)$. Interestingly, the concepts of D70 (the minimum absorbed dose delivered to $70 \%$ of the $T$ volume) and V100 (the percentage $T$ volume receiving $\geq 100 \mathrm{~Gy}$ ) were proposed for $T$ reporting from EBRT. D70 = 100 Gy was derived as a threshold for complete versus incomplete responses. Comparing the mean absorbed doses ${ }^{90} \mathrm{Y}-\mathrm{PET}$ and ${ }^{99 \mathrm{~m}} \mathrm{Tc}-\mathrm{MAA}-\mathrm{SPECT}$ imaging, a good correlation was found in 7 lesions under near-ideal dosimetric conditions (i.e., case 
of technically success, $\mathrm{T} / \mathrm{NL}$ ratio $\geq 2$, good activity coverage), with a relative error ranging from -2 to $13 \%$.

\section{Glass spheres}

In a study previously discussed for toxicity, Riaz et al. (80) planned the activity in order to deliver 120 Gy to the lobe/segment, by the mono-compartmental method. Retrospectively, for comparison purposes, a method based on the iodinated contrast medium distribution was used to evaluate the absorbed dose to $T$ and NL. Tumor received 1214 (961-1546) Gy. The response rate evaluated by WHO (dimension criteria) was 59\% (after 7.2 months), and that evaluated by EASL (density criteria) was $81 \%$ (after 1.2 months). The study confirms the correspondence of high efficacy with high $T$ absorbed doses. However, the difference of $T$ absorbed doses between responding (EASL 1279 [986-1626] Gy) and non-responding (EASL (1118 [332-2139] Gy) lesions was not statistically significant, possibly because of the questionable method of assigning the $T / \mathrm{NL}$ uptake.

Sarfaraz et al. (100) used the standard method of 150 Gy to the treated lobe to establish the administered activity. They retrospectively analyzed 10 patients using the data from total body images ( ${ }^{99 \mathrm{~m}}$ Tc-MAA scan) as input to the compartmental (partition) method. The activity distribution in the liver was found to be highly non-uniform, with different T/NL uptakes. For a typical patient, the absorbed doses to the $T$ and NL were 402 and $118 \mathrm{~Gy}$, respectively. The NL median dose with non-compartmental and compartmental model were statistically different $(141 \pm 12$ Gy versus $117 \pm 23 \mathrm{~Gy}$ ). The authors pointed out the need to distinguish $T$ to NL absorbed dose in order to avoid high risk of over- or underdosage, and possibly to estimate the overall dose distribution.

In a subsequent paper (54), the same authors account the voxel activity distribution in a patient from ${ }^{99 \mathrm{~m}}$ Tc-MAA SPECT images retrospectively analyzed, with isodose curves and DVHs derived for $T$ and NL. The DVHs indicated that although the patient was treated to the nominal whole liver dose of $110 \mathrm{~Gy}$, only $16 \%$ of NL and $83 \%$ of the $T$ received a dose higher than $110 \mathrm{~Gy}$. The mean $T$ absorbed dose was $163 \mathrm{~Gy}$.

In a retrospective study, Garin et al. (14) analyzed 36 patients with HCC. The activity was based on ${ }^{99 \mathrm{~m}} \mathrm{Tc}$-SPECT/CT images in order to deliver an absorbed dose to the liver of $120 \pm 20 \mathrm{~Gy}$ (without exceeding $30 \mathrm{~Gy}$ to lungs). The absorbed dose to the $T\left(D_{\mathrm{T}}\right)$ and to NL were also determined. $69 \%$ of patients responded (EASL criteria). A multivariate analysis identified $D_{\mathrm{T}}$ as the only parameter associated with response, with the value of $205 \mathrm{~Gy}$ as threshold predictive of response, a sensitivity of $100 \%$, and an accuracy of $91 \%$. PFS and OS were 5.2 and 9 months when $D_{\mathrm{T}}<205 \mathrm{~Gy}$, whilst with $D_{\mathrm{T}} \geq 205$ Gy they were, respectively, 14 and 18 months. This study highlighted the utility of ${ }^{99 \mathrm{~m}}$ Tc-MAA SPECT/CT dosimetry, in predicting both response and survival.

These preliminary results were confirmed in a larger cohort of 71 HCC patients (21), with the same threshold of $D_{\mathrm{T}}=205 \mathrm{~Gy}$ for $T$ response. The response rate was $79 \%$, with a median $D_{\mathrm{T}}$ of $342 \mathrm{~Gy}$ and of $191 \mathrm{~Gy}$ for responding and non-responding $T$, respectively, with a statistically significant difference. Based on the predicted $D_{\mathrm{T}}$ and $D_{\mathrm{NL}}, 17$ patients underwent a boosted RE (increased injected activity with respect to 120 Gy prescription) that provided a good response rate $(77 \%)$ without increased
G3 liver toxicity. Median PFS and OS were only slightly different from the previous study. In 33 PVT patients, the median PFS and OS were 4.5 and 5 months when $D_{\mathrm{T}}<205 \mathrm{~Gy}$, whilst with $D_{\mathrm{T}} \geq 205 \mathrm{~Gy}$ they were, respectively, 10 and 22 months. The authors remark the predictivity of ${ }^{99 \mathrm{~m}} \mathrm{Tc}-\mathrm{MAA}$ SPECT/CT dosimetry on response and OS, and point out the possibility to adapt the treatment planning especially in patients with large $T$, e.g., intensifying the treatment without increasing liver toxicity (boosted RE concept).

In the retrospective dosimetry on ${ }^{99 \mathrm{~m}} \mathrm{Tc}-\mathrm{MAA}$ SPECT images by Mazzaferro et al. (75), EASL lesion response (CR $+\mathrm{PR})$ correlated with absorbed dose (Spearman's $r=0.60$; 95\%CI, $0.41-$ $0.74 ; P<0.001)$. Lesions lacking of objective response received a median dose of $275 \mathrm{~Gy}$, whereas responding tumors were found to absorb $490 \mathrm{~Gy}(P<0.0001)$. An efficacy threshold of 500 Gy significantly predicted the observed objective response and limited to $20 \%$ the rate of non-responders (area under the curve $=0.78)$.

\section{TAKE HOME MESSAGES FROM DOSE-EFFECTS CORRELATIONS}

For the first time in nuclear medicine therapy, a dose-effect relation was indicated (observed), even though data are sparse and obtained with non-uniform methods. This is more evident for lesions, while a liver toxicitydose relation is reported in fewer papers. Several bias impede to find sharper dose thresholds: the heterogeneity of the end points considered, different basal liver conditions, the natural history of cirrhosis in HCC patients, the previous chemotherapy cycles for metastatic cases. Dosimetric methods are still not uniform but they are improving quickly. After the application in peptide radionuclide therapy (10), the radiobiological modeling (NTCP and TCP curves) inherited from EBRT has been applied to RE to describe the observed clinical data (16) and to plan treatments (13). The efforts made highlight several interesting issues that fit dosimetric and radiobiological perspectives. These are summarized for side effects and $T$ responses in the following.

\section{Side effects}

- Administered activity alone does not appear to be a valid predictor of treatment safety compared to accurate estimation of absorbed dose (28 cases of death occurred although activities were not particularly high) (24). The empirical method has been excluded from recommendation. Despite its popularity, the BSA method represents a non-dosimetric approach and is radiobiologically questionable (22). The role of ${ }^{99 m} \mathrm{Tc}-\mathrm{MAA}$ simulation is relevant, to avoid treatments with inappropriate activity distribution $(14,53)$.

- For resin spheres, the dosimetry with ${ }^{99 \mathrm{~m}} \mathrm{Tc}-\mathrm{MAA}$ and the compartmental model was able to find out the indication for liver toxicity beyond $40 \mathrm{~Gy}$ to the whole liver $(35,101)$ - which is not far from EBRT limits (15). The BED 50 of 93 Gy by Strigari et al. (16) in HCC patients is not so far from the BED 50 of $72 \mathrm{~Gy}$ deduced from EBRT (70). In case of nearly uniform activity distribution, values for severe toxicity were comparable with those from EBRT (53).

- For glass spheres, authors acknowledge that the lack of distinction between $T$ and NL is a major limitation $(82,100)$, as 
such distinction has a great impact on the evaluations derived (e.g., median absorbed dose to the liver segment of 520 versus $210 \mathrm{~Gy}$ by the usual glass method versus the revised method) $(14,21,80)$. In any case, in glass spheres, increasing cumulative absorbed doses were found to increment liver toxicities (79). The NTCP reported in Figure 3 by Chiesa et al. is the first indication of augmented risk with absorbed dose averaged on the NL parenchyma for HCC patients. 70 Gy seems a good value to keep the incidence of liver decompensation below 20\%.

- About lung tolerance, the present safety limits (dose < $30 \mathrm{~Gy}$ ) were obtained for resin spheres on planar images non-corrected for attenuation. The correction leads this threshold close to the known value from EBRT $(17.5 \mathrm{~Gy})$. For glass spheres, the question is completely open.

- Dosimetry from post-RE images (Bremsstrahlung-SPECT but above all ${ }^{90}$ Y-PET) could improve the dose-effect correlations bypassing the problem of correspondence between MAA and microspheres $(16,49,50,53)$. The voxel dosimetry enriched the information about the degree of non-uniformity $(50,51,53)$.

- The LQM was proposed as rationale to guide therapy decisions and absorbed dose-escalation studies involving re-treatment and partial liver irradiations (volume effects). The radiobiological methods used in EBRT to derive NTCP and TCP curves have been applied to RE to predict toxicity and response (16).

- The radiobiological parameters can consistently influence the radiobiological entities such as EUBED or EUD, and should be determined specifically for the tissues under investigation, in NL and different $T$. (51)

- The liver volume effect well known in EBRT has been confirmed also in RE, where the irradiation of a small organ fraction gave very limited toxicity $(72,80)$. A large irradiated volume with high dose is a risk factor (21).

- As in EBRT, the basal liver status deriving from underlying disease (cirrhosis) or concomitant or previous treatment (chemotherapy, TACE) results in markedly different dose tolerance $(13,59,79)$. A systematic absorbed dose-escalation study would need the same conditions of the patients included (79).

\section{Tumor response}

- There is not a univocal evaluation criteria of $T$ response $(16,35)$. - In resin spheres, ${ }^{99 \mathrm{~m}} \mathrm{Tc}$-MAA has provided essential information for patient recruitment to RE (35), preventing treatments without proper activity distribution (53). Lesion dosimetry correlated with metabolic response $(17,35,50)$ as well as with radiologic response $(14,16,39,75)$.

- The voxel dosimetry approach is more and more applied, with potential improvement of predictive power of dosimetry. DVHs are derived, the degree of non-uniformity analyzed (17, 50, 51), and the EUBED, EUD, EQ2 parameters evaluated. Recently, the "planning target volume" concept has been proposed with D70 and V100 as parameters for response and toxicity as for EBRT (22).

- There is clinical evidence of a same biological effect (toxicity and efficacy) related to different median absorbed doses for glass and resin microspheres (110-120 Gy versus $45-50$ to the single lobe) following the different number of spheres per GBq, i.e., per Gy $(2,84)$.

- In glass spheres, the utility of ${ }^{99 \mathrm{~m}} \mathrm{Tc}$-MAA-SPECT/CT dosimetry has been confirmed in predicting both response and survival, and adapting the treatment planning especially in patients with large $T(14,21)$. An absorbed dose of $205 \mathrm{~Gy}$ represents the threshold for improved survival. Based on the dose distribution analysis, some patients could benefit of a boosted RE without increased G3 liver toxicity.

\section{CONCLUSION}

The proposed review offers a comprehensive summary of the results and shows many successful steps reached when dosimetry and radiobiological models have been used. Methods from EBRT are ready to be inherited and/or adapted to RE applications. Some dose-effects correlations are still weak or improvable, but others have been robustly found, allowing to predict toxicity, response, and survival. Individualized dosimetric treatment planning in $\mathrm{RE}$ is feasible. This might definitely improve the management of primary and metastatic liver cancer.

\section{REFERENCES}

1. Gulec SA, Sztejnberg ML, Siegel JA, Jevremovic T, Stabin M. Hepatic structural dosimetry in $(90) \mathrm{Y}$ microsphere treatment: a Monte Carlo modeling approach based on lobular microanatomy. J Nucl Med (2010) 51:301-10. doi:10.2967/jnumed.109.069278

2. Spreafico C, Maccauro M, Mazzaferro V, Chiesa C. The dosimetric importance of the number of $90 \mathrm{Y}$ microspheres in liver transarterial radioembolization (TARE). Eur J Nucl Med Mol Imaging (2014) 41:634-8. doi:10.1007/s00259013-2674-6

3. Therasphere ${ }^{\circledR}$ by BTG. (http://www.therasphere.com). Available from: http://www.therasphere.com/physicians-package-insert/package-insert-euen.pdf

4. SIR-Spheres Yttrium-90 Microspheres [Package Insert]. Lane Cove: Sirtex Medical (2004). Available from: http://www.sirtex.com/files/ US20Package20Insert1.pdf

5. Riaz A, Lewandowski RJ, Kulik LM, Mulcahy MF, Sato KT, Ryu RK, et al. Complications following radioembolization with yttrium- 90 microspheres: a comprehensive literature review. J Vasc Interv Radiol (2009) 20:1121-30. doi:10.1016/j.jvir.2009.05.030

6. Sangro B, Iñarrairaegui M, Bilbao JI. Radioembolization for hepatocellular carcinoma. J Hepatol (2012) 56:464-73. doi:10.1016/j.jhep.2011.07.012

7. Salem R, Thurston KG. Radioembolization with 90Yttrium microspheres: a state-of-the-art brachytherapy treatment for primary and secondary liver malignancies. Part 2: special topics. J Vasc Interv Radiol (2006) 17:1425-39. doi:10.1097/01.RVI.0000235779.88652.53

8. Van De Wiele C, Defreyne L, Peeters M, Lambert B. Yttrium-90 labelled resin microspheres for treatment of primary and secondary malignant liver tumors. Q J Nucl Med Mol Imaging (2009) 53:317-24.

9. Barone R, Borson-Chazot F, Valkema R, Walrand S, Chauvin F, Gogou L, et al. Patient-specific dosimetry in predicting renal toxicity with (90)Y-DOTATOC: relevance of kidney volume and dose rate in finding a dose-effect relationship. J Nucl Med (2005) 46(Suppl 1):99S-106S.

10. Wessels BW, Konijnenberg MW, Dale RG, Breitz HB, Cremonesi M, Meredith RF, et al. MIRD pamphlet No. 20: the effect of model assumptions on kidney dosimetry and response - implications for radionuclide therapy. J Nucl Med (2008) 49:1884-99. doi:10.2967/jnumed.108.053173 Erratum in: J Nucl Med (2011) 52:1498,

11. Strigari L, Benassi M, Chiesa C, Cremonesi M, Bodei L, D'Andrea M. Dosimetry in nuclear medicine therapy: radiobiology application and results. Q J Nucl Med Mol Imaging (2011) 55:205-21.

12. Chiesa C, Maccauro M, Romito R, Spreafico C, Pellizzari S, Negri A, et al. Need, feasibility and convenience of dosimetric treatment planning in liver selective internal radiation therapy with $(90) \mathrm{Y}$ microspheres: the experience 
of the National Tumor Institute of Milan. Q J Nucl Med Mol Imaging (2011) 55:168-97.

13. Chiesa C, Mira M, Maccauro M, Romito R, Spreafico C, Sposito C, et al. A dosimetric treatment planning strategy in radioembolization of hepatocarcinoma with $90 \mathrm{Y}$ glass microspheres. Q J Nucl Med Mol Imaging (2012) 56:503-8

14. Garin E, Lenoir L, Rolland Y, Edeline J, Mesbah H, Laffont S, et al. Dosimetry based on $99 \mathrm{mTc}$-macroaggregated albumin SPECT/CT accurately predicts tumor response and survival in hepatocellular carcinoma patients treated with 90Y-loaded glass microspheres: preliminary results. J Nucl Med (2012) 53:255-63. doi:10.2967/jnumed.111.094235

15. Cremonesi M, Ferrari M, Bartolomei M, Orsi F, Bonomo G, Aricò D, et al. Radioembolization with 90Y-microspheres: dosimetric and radiobiological investigation for multi-cycle treatment. Eur J Nucl Med Mol Imaging (2008) 35:2088-96. doi:10.1007/s00259-008-0857-3

16. Strigari L, Sciuto R, Rea S, Carpanese L, Pizzi G, Soriani A, et al. Efficacy and toxicity related to treatment of hepatocellular carcinoma with $90 \mathrm{Y}$ SIR spheres: radiobiological considerations. J Nucl Med (2010) 51:1377-85. doi:10.2967/jnumed.110.075861

17. Lhommel R, van Elmbt L, Goffette P, Van den Eynde M, Jamar F, Pauw els $\mathrm{S}$, et al. Feasibility of $90 \mathrm{Y}$ TOF PET-based dosimetry in liver metastasis therapy using SIR-spheres. Eur J Nucl Med Mol Imaging (2010) 37:1654-62. doi:10.1007/s00259-010-1470-9

18. Gates VL, Esmail AA, Marshall K, Spies S, Salem R. Internal pair production of 90Y permits hepatic localization of microspheres using routine PET: proof of concept. J Nucl Med (2011) 52:72-6. doi:10.2967/jnumed.110.080986

19. Murthy R, Xiong H, Nunez R, Cohen AC, Barron B, Szklaruk J, et al. Yttrium 90 resin microspheres for the treatment of unresectable colorectal hepatic metastases after failure of multiple chemotherapy regimens: preliminary results. J Vasc Interv Radiol (2005) 16:937-45. doi:10.1097/01.RVI.0000161142. 12822.66

20. Giammarile F, Bodei L, Chiesa C, Flux G, Forrer F, Kraeber-Bodere F, et al. EANM procedure guidelines for the treatment of liver cancer and liver metastases with intra-arterial radioactive compounds. Eur J Nucl Med Mol Imaging (2011) 38:1393-406. doi:10.1007/s00259-011-1812-2

21. Garin E, Lenoir L, Edeline J, Laffont S, Mesbah H, Porée P, et al. Boosted selective internal radiation therapy with 90Y-loaded glass microspheres (BSIRT) for hepatocellular carcinoma patients: a new personalized promising concept. Eur J Nucl Med Mol Imaging (2013) 40:1057-68. doi:10.1007/s00259013-2395-x

22. Kao YH, Hock Tan AE, Burgmans MC, Irani FG, Khoo LS, Gong Lo RH, et al. Image-guided personalized predictive dosimetry by artery-specific SPECT/CT partition modeling for safe and effective $90 \mathrm{Y}$ radioembolization. J Nucl Med (2012) 53:559-66. doi:10.2967/jnumed.111.097469

23. Stabin MG, Sparks RB, Crowe E. OLINDA/EXM: the second-generation personal computer software for internal dose assessment in nuclear medicine. $J$ Nucl Med (2005) 46:1023-7.

24. Kennedy AS, McNeillie P, Dezarn WA, Nutting C, Sangro B, Wertman D, et al. Treatment parameters and outcome in 680 treatments of internal radiation with resin 90Y-microspheres for unresectable hepatic tumors. Int JRadiat Oncol Biol Phys (2009) 74:1494-500. doi:10.1016/j.ijrobp.2008.10.005

25. Ferrari M, Cremonesi M, Bartolomei De Cicco C, Bonomo G, Orsi F, Travaini LL, et al. Different evaluations for safe 90Y-microspheres in Selective Internal Radiation Therapy (SIRT). Eur J Nucl Med Mol Imaging (2007) 34(Suppl 2):S178.

26. Ho S, Lau WY, Leung TW, Chan M, Ngar YK, Johnson PJ, et al. Partition model for estimating radiation doses from yttrium-90 microspheres in treating hepatic tumours. Eur J Nucl Med (1996) 23:947-52. doi:10.1007/BF01084369

27. Gulec SA, Mesoloras G, Stabin M. Dosimetric techniques in 90Y-microsphere therapy of liver cancer: The MIRD equations for dose calculations. J Nucl Med (2006) 47:1209-11.

28. Salem R, Thurston KG. Radioembolization with 90Yttrium microspheres: a state-of-the-art brachytherapy treatment for primary and secondary liver malignancies. Part 1: Technical and methodologic considerations. J Vasc Interv Radiol (2006) 17:1251-78. Erratum in: J Vasc Interv Radiol (2006) 17:1594. doi:10.1097/01.RVI.0000235779.88652.53

29. Ulrich G, Dudeck O, Furth C, Ruf J, Grosser OS, Adolf D, et al. Predictive value of intratumoral $99 \mathrm{mTc}$-macroaggregated albumin uptake in patients with colorectal liver metastases scheduled for radioembolization with
90Y-microspheres. J Nucl Med (2013) 54:516-22. doi:10.2967/jnumed.112. 112508

30. Wondergem M, Smits ML, Elschot M, de Jong HW, Verkooijen HM, van den Bosch MA, et al. $99 \mathrm{mTc}$-macroaggregated albumin poorly predicts the intrahepatic distribution of $90 \mathrm{Y}$ resin microspheres in hepatic radioembolization. $J$ Nucl Med (2013) 54:1294-301. doi:10.2967/jnumed.112.117614

31. Knesaurek K, Machac J, Muzinic M, DaCosta M, Zhang Z, Heiba S. Quantitative comparison of yttrium-90 (90Y)-microspheres and technetium-99m ( $99 \mathrm{mTc})$-macroaggregated albumin SPECT images for planning 90Y therapy of liver cancer. Technol Cancer Res Treat (2010) 9:253-62.

32. Jiang M, Fishman A, Nowakowski FS, Heiba S, Zhang Z, Knesaurek K, et al. Segmental perfusion differences on paired Tc- $99 \mathrm{~m}$ macroaggregated albumin (MAA) hepatic perfusion imaging and yttrium-90 8Y-90) bremstrahlung imaging studies in SIR-spere radioembolization: associations with angiography. J Nucl Med Radiat Ther (2012) 3:1. doi:10.4172/2155-9619.1000122

33. Chiesa C, Lambert B, Maccauro M, Ezziddin S, Ahmadzadehfar H, Dieudonné A, et al. The predictive power of 99mTc-MAA SPECT/CT on lesion response cannot be invalidated for all kind of lesions and all kind of $90 \mathrm{Y}$ microspheres by a barely visual evaluation of the uptake and a RECIST response evaluation of colorectal metastases treated with resin microspheres. J Nucl Med (2014) 55:1215-16. doi:10.2967/jnumed.113.129361

34. Ahmadzadehfar H, Sabet A, Biermann K, Muckle M, Brockmann H, Kuhl C, et al. The significance of $99 \mathrm{mTc}$-MAA SPECT/CT liver perfusion imaging in treatment planning for 90Y-microsphere selective internal radiation treatment. J Nucl Med (2010) 51:1206-12. doi:10.2967/jnumed.109.074559

35. Flamen P, Vanderlinde B, Delatte P, Ghanem G, Ameye L, Van Den Eynde $\mathrm{M}$, et al. Multimodality imaging can predict the metabolic response of unresectable colorectel liver metastases to radioembolization therapy with yttrium90 labeled resin micropheres. Phys Med Biol (2008) 53:6591-603. doi:10.1088/ 0031-9155/53/22/019

36. Kao YH, Steinberg JD, Tay YS, Lim GK, Yan J, Townsend DW, et al. Postradioembolization yttrium-90 PET/CT - part 2: dose-response and tumor predictive dosimetry for resin microspheres. EJNMMI Res (2013) 3:57. doi:10. 1186/2191-219X-3-57

37. Guerriero F, Ferrari M, Botta F, Pedroli G, Grana C, Chiesa C, et al. Brachytherapy of Liver Lesions with 90Y-Microspheres: Comparing Previsional and Post-Therapy Dosimetry. Accepted abstract at the ESTRO (European Society of Radiotherapy and Oncology) meeting 2014. Radiother Oncol (2014) 111(Suppl 1):754.

38. Pettinato C, Fracchetti A, Civollani S, Monari F, Gavaruzzi G, Giampalma E, et al. Is it possible to perform voxel dosimetry in a simple way in patients treated with Selective Internal Radio Therapy using 90Y microspheres? Eur J Nucl Med Mol Imaging (2013) 40(Suppl 2):O624.

39. Campbell JM, Wong CO, Muzik O, Marples B, Joiner M, Burmeister J. Early dose response to yttrium-90 microsphere treatment of metastatic liver cancer by a patient-specific method using single photon emission computed tomography and positron emission tomography. Int J Radiat Oncol Biol Phys (2009) 74:313-20. doi:10.1016/j.ijrobp.2008.12.058

40. Ho S, Lau WY, Leung TWT, Chan M, Johnson PJ, Li AK. Clinical evaluation of the partition model for estimate radiation doses from yttrium- 90 microspheres in the treatment of hepatic cancer. Eur J Nucl Med (1997) 24:293-8. doi:10.1007/BF01728766

41. Lau WY, Leung WT, Ho S, Leung NW, Chan M, Lin J, et al. Treatment of inoperable hepatocellular carcinoma with intrahepatic arterial yttrium90 microspheres: a phase I and II study. Br J Cancer (1994) 70:994-9. doi:10.1038/bjc. 1994.436

42. Lau WY, Kennedy AS, Kim YH, Lai HK, Lee RC, Leung TW, et al. Patient selection and activity planning guide for selective internal radiotherapy with yttrium-90 resin microspheres. Int J Radiat Oncol Biol Phys (2012) 82:401-7. doi:10.1016/j.ijrobp.2010.08.015

43. Ahmadzadehfar H, Muckle M, Sabet A, Wilhelm K, Kuhl C, Biermann K, et al. The significance of bremsstrahlung SPECT/CT after yttrium-90 radioembolization treatment in the prediction of extrahepatic side effects. Eur J Nucl Med Mol Imaging (2012) 39:309-15. doi:10.1007/s00259-011-1940-8

44. Ahmadzadehfar H, Sabet A, Muckle M, Wilhelm K, Reichmann K, Biersack HJ, et al. 99mTc-MAA/90Y-Bremsstrahlung SPECT/CT after simultaneous TcMAA/90Y-microsphere injection for immediate treatment monitoring and further therapy planning for radioembolization. Eur J Nucl Med Mol Imaging (2011) 38:1281-8. doi:10.1007/s00259-011-1751-y 
45. Minarik D, Sjögreen Gleisner K, Ljungberg M. Evaluation of quantitative (90)Y SPECT based on experimental phantom studies. Phys Med Biol (2008) 53:5689-703. doi:10.1088/0031-9155/53/20/008

46. Minarik D, Ljungberg M, Segars P, Gleisner KS. Evaluation of quantitative planar $90 \mathrm{Y}$ bremsstrahlung whole-body imaging. Phys Med Biol (2009) 54:5873-83. doi:10.1088/0031-9155/54/19/014

47. Walrand S, Hesse M, Demonceau G, Pauwels S, Jamar F. Yttrium-90labeled microsphere tracking during liver selective internal radiotherapy by bremsstrahlung pinhole SPECT: feasibility study and evaluation in an abdominal phantom. EJNMMI Res (2011) 1:32. doi:10.1186/2191-219X-1-32

48. Willowson K, Forwood N, Jakoby BW, Smith AM, Bailey DL. Quantitative 90Y image reconstruction in PET. Med Phys (2012) 39:7153-9. doi:10.1118/1. 4762403

49. D’Arienzo M, Chiaramida P, Chiacchiararelli L, Coniglio A, Cianni R, Salvatori $\mathrm{R}$, et al. 90Y PET-based dosimetry after selective internal radiotherapy treatments. Nucl Med Commun (2012) 33:633-40. doi:10.1097/MNM. 0b013e3283524220

50. D’Arienzo M, Filippi L, Chiaramida P, Chiacchiararelli L, Cianni R, Salvatori R, et al. Absorbed dose to lesion and clinical outcome after liver radioembolization with $90 \mathrm{Y}$ microspheres: a case report of PET-based dosimetry. Ann Nucl Med (2013) 27:676-80. doi:10.1007/s12149-013-0726-4

51. Di Dia A, Cremonesi M, Botta F, Ferrari M, Prisco G, Wessels B, et al. Impact of $3 \mathrm{D}$ dosimetric and radiobiological estimates methods in radioembolisation of liver metastasis with 90Y-microspheres. Eur J Nucl Med Mol Imaging (2011) 38(Suppl 2):S94,O022.

52. Walrand S, Lhommel R, Goffette P, Van den Eynde M, Pauwels S, Jamar F. Hemoglobin level significantly impacts the tumor cell survival fraction in humans after internal radiotherapy. EJNMMI Res (2012) 2:20. doi:10.1186/ 2191-219X-2-20

53. Bagni O, Filippi L, Salvatori R, D’Agostini A, Cianni R, Notarianni E, et al. Voxel dosimetry with 90Y-PET for the assessment of liver toxicity. Eur J Nucl Med Mol Imaging (2012) 39(Suppl 2):S337, O131.

54. Sarfaraz M, Kennedy AS, Lodge MA, Li XA, Wu X, Yu CX. Radiation absorbed dose distribution in a patient treated with yttrium-90 microspheres for hepatocellular carcinoma. Med Phys (2004) 31:2449-53. doi:10.1118/1.1781332

55. Fox RA, Phil D, Klemp PFB, Egan G, Mina LL, Burton MA, et al. Dose distribution following selective internal radiation therapy. Int J Radiat Oncol Biol Phys (1991) 21:463-7. doi:10.1016/0360-3016(91)90797-8

56. Kennedy AS, Nutting C, Coldwell D, Gaiser J, Drachenberg C. Pathologic response and microdosimetry of (90)Y microspheres in man: review of four explanted whole livers. Int J Radiat Oncol Biol Phys (2004) 60:1552-63. doi:10.1016/j.ijrobp.2004.09.004

57. Yorke ED, Jackson A, Fox RA, Wessels BW, Gray BN. Can current models explain the lack of liver complications in Y-90 microsphere therapy? Clin Cancer Res (1999) 5(Suppl):3024s-30s.

58. Andrews JC, Walker SC, Ackermann RJ, Cotton LA, Ensminger WD, Shapiro B. Hepatic radioembolization with Yttrium- 90 containing glass microspheres: preliminary results and clinical follow-up. J Nucl Med (1994) 35:1637-44.

59. Sangro B, Gil-Alzugaray B, Rodriguez J, Sola I, Martinez-Cuesta A, Viudez A, et al. Liver disease induced by radioembolization of liver tumors: description and possible risk factors. Cancer (2008) 112:1538-46. doi:10.1002/cncr. 23339

60. Walrand S, Hesse M, Chiesa C, Lhommel R, Jamar F. The low hepatic toxicity per Gray of $90 \mathrm{Y}$ glass microspheres is linked to their transport in the arterial tree favoring a nonuniform trapping as observed in post therapy PET imaging. J Nucl Med (2014) 55:135-40. doi:10.2967/jnumed.113.126839

61. Nace GW, Steel JL, Amesur N, Zajko A, Nastasi BE, Joyce J, et al. Yttrium-90 radioembolization for colorectal cancer liver metastases: a single institution experience. Int J Surg Oncol (2011) 2011:571261. doi:10.1155/2011/571261

62. Bilbao JI, de Martino A, de Luis E, Díaz-Dorronsoro L, Alonso-Burgos A, Martínez de la Cuesta A, et al. Biocompatibility, inflammatory response, and recanalization characteristics of nonradioactive resin microspheres: histological findings. Cardiovasc Intervent Radiol (2009) 32:727-36. doi:10.1007/ s00270-009-9592-9

63. Lewandowski RJ, Minocha J, Memon K, Riaz A, Gates VL, Ryu RK, et al. Sustained safety and efficacy of extended-shelf-life $90 \mathrm{Y}$ glass microspheres: longterm follow-up in a 134-patient cohort. Eur J Nucl Med Mol Imaging (2014) 41:486-93. doi:10.1007/s00259-013-2575-8
64. O'Donogue JA. Implications of non-uniform tumor doses for radioimmunotherapy. J Nucl Med (1999) 40:1337-41.

65. Ferrari ME, Cremonesi M, Di Dia A, Botta F, De Cicco C, Sarnelli A, et al. 3D dosimetry in patients with early breast cancer undergoing Intraoperative Avidination for Radionuclide Therapy (IART) combined with external beam radiation therapy. Eur J Nucl Med Mol Imaging (2012) 39:1702-11. doi:10.1007/s00259-012-2197-6

66. Burman C, Kutcher GJ, Emami B, Goitein M. Fitting of normal tissue tolerance data to an analytic function. Int J Radiat Oncol Biol Phys (1991) 21:123-35. doi:10.1016/0360-3016(91)90172-Z

67. Kutcher GJ, Burman C. Calculation of complication probability factors for non-uniform normal tissue irradiation: the effective volume method. Int J Radiat Oncol Biol Phys (1989) 16:1623-30. doi:10.1016/0360-3016(89) 90972-3

68. Antipas V, Dale RG, Coles IP. A theoretical investigation into the role of tumour radiosensitivity, clonogen repopulation, tumour shrinkage and radionuclide RBE in permanent brachytherapy implants of 125I and 103Pd. Phys Med Biol (2001) 46:2557-69. doi:10.1088/0031-9155/46/10/304

69. Jones B, Dale RG. Mathematical models of tumour and normal tissue response. Acta Oncol (1999) 38:883-93. doi:10.1080/028418699432572

70. Emami B, Lyman J, Brown A, Coia L, Goitein M, Munzenrider JE, et al. Tolerance of normal tissue to therapeutic irradiation. Int J Radiat Oncol Biol Phys (1991) 21:109-22. doi:10.1016/0360-3016(91)90171-Y

71. Dawson LA, Lawrence TS, Yen Haken RK. Partial liver irradiation. Semin Radiat Oncol (2001) 11:240-6. doi:10.1053/srao.2001.23485

72. Rhee TK, Omary RA, Gates V, Mounajjed T, Larson AC, Barakat O, et al. The effect of catheter-directed CT angiography on yttrium-90 radioembolization treatment of hepatocellular carcinoma. J Vasc Interv Radiol (2005) 16:1085-91. doi:10.1097/01.RVI.0000177063.92678.21

73. Dawson LA, Normolle D, Balter JM, McGinn CJ, Lawrence TS, Ten Haken RK. Analysis of radiation-induced liver disease using the Lyman NTCP model. Int J Radiat Oncol Biol Phys (2002) 53(4):810-21. Erratum in: Int J Radiat Oncol Biol Phys (2002) 53:1422. doi:10.1016/S0360-3016(02)02846-8

74. Wright CL, Werner JD, Tran JM, Gates VL, Rikabi AA, Shah MH, et al. Radiation pneumonitis following yttrium-90 radioembolization: case report and literature review. J Vasc Interv Radiol (2012) 23:669-74. doi:10.1016/j.jvir.2012. 01.059

75. Mazzaferro V, Sposito C, Bhoori S, Romito R, Chiesa C, Morosi C, et al. Yttrium90 radioembolization for intermediate-advanced hepatocarcinoma: a phase II study. Hepatology (2013) 57:1826-37. doi:10.1002/hep.26014

76. Hilgard P, Hamami M, El Fouly A, Scherag A, Müller S. Ertle J, et al. Radioembolization with yttrium-90 glass microspheres in hepatocellular carcinoma: European Experience on Safety and Long-Term Survival. Hepatology (2010) 52:1741-9. doi:10.1002/hep.23944

77. Lam MG, Abdelmaksoud MH, Chang DT, Eclov NC, Chung MP, Koong AC, et al. Safety of $90 \mathrm{Y}$ radioembolization in patients who have undergone previous external beam radiation therapy. Int J Radiat Oncol Biol Phys (2013) 87:323-9. doi:10.1016/j.ijrobp.2013.05.041

78. Gulec SA, Mesoloras G, Dezarn WA, McNeillie P, Kennedy AS. Safety and efficacy of Y-90 microsphere treatment in patients with primary and metastatic liver cancer: the tumor selectivity of the treatment as a function of tumor to liver flow ratio. J Transl Med (2007) 5:15. doi:10.1186/1479-58765-15

79. Young JY, Rhee TK, Atassi B, Gates VL, Kulik L, Mulcahy MF, et al. Radiation dose limits and liver toxicities resulting from multiple yttrium-90 radioembolization treatments for hepatocellular carcinoma. J Vasc Interv Radiol (2007) 18:1375-82. doi:10.1016/j.jvir.2007.07.016

80. Riaz A, Gates VL, Atassi B, Lewandowski RJ, Mulcahy MF, Ryu RK, et al. Radiation segmentectomy: a novel approach to increase safety and efficacy of radioembolization. Int J Radiat Oncol Biol Phys (2011) 79:163-71. doi:10.1016/j.ijrobp.2009.10.062

81. Goin JE, Salem R, Carr BI, Dancey JE, Soulen MC, Geschwind JF, et al. Treatment of unresectable hepatocellular carcinoma with intrahepatic yttrium 90 microspheres: factors associated with liver toxicities. J Vasc Interv Radiol (2005) 16(2):205-13. doi:10.1097/01.RVI.00001142592.89564.F9

82. Dancey JE, Shepherd FA, Paul K, Sniderman KW, Houle S, Gabrys J, et al. Treatment of nonresectable hepatocellular carcinoma with intrahepatic 90Ymicrospheres. J Nucl Med (2000) 41:1673-81. 
83. Geschwind JF, Salem R, Carr BI, Soulen MC, Thurston KG, Goin KA, et al. Yttrium-90 microspheres for the treatment of hepatocellular carcinoma. Gastroenterology (2004) 127(5 Suppl 1):S194-205. doi:10.1053/j.gastro.2004. 09.034

84. Rhee TK, Lewandowski RJ, Liu DM, Mulcahy MF, Takahashi G, Hansen PD, et al. 90Y Radioembolization for metastatic neuroendocrine liver tumors: preliminary results from a multi-institutional experience. Ann Surg (2008) 247:1029-35. doi:10.1097/SLA.0b013e3181728a45

85. Vente MA, Hobbelink MG, van Het Schip AD, Zonnenberg BA, Nijsen JF. Radionuclide liver cancer therapies: from concept to current clinical status. Anticancer Agents Med Chem (2007) 7:441-59. doi:10.2174/ 187152007781058569

86. Goin JE, Salem R, Carr BI, Dancey JE, Soulen MC, Geschwind JF, et al. Treatment of unresectable hepatocellular carcinoma with intrahepatic yttrium 90 microspheres: a risk-stratification analysis. J Vasc Interv Radiol (2005) 16 (2 Pt 1):195-203. doi:10.1097/01.RVI.0000142602.79459.90

87. Petitguillaume A, Bernardini M, Hadid L, de Labriolle-Vaylet C, Franck D, Desbrée A. Three-dimensional personalized Monte Carlo dosimetry in $90 \mathrm{Y}$ resin microspheres therapy of hepatic metastases: nontumoral liver and lungs radiation protection considerations and treatment planning optimization. $\mathrm{J} \mathrm{Nucl}$ Med (2014) 55:405-13. doi:10.2967/jnumed.113.120444

88. Salem R, Parikh P, Atassi B, Lewandowski RJ, Ryu RK, Sato KT, et al. Incidence of radiation pneumonitis after hepatic intra-arterial radiotherapy with yttrium-90 microspheres assuming uniform lung distribution. Am J Clin Oncol (2008) 31:431-8. doi:10.1097/COC.0b013e318168ef65

89. Leung TW, Lau WY, Ho SK, Ward SC, Chow JH, Chan MS, et al. Radiation pneumonitis after selective internal radiation treatment with intraarterial 90yttrium-microspheres for inoperable hepatic tumors. Int J Radiat Oncol Biol Phys (1995) 33:919-24. doi:10.1016/0360-3016(95)00039-3

90. Claude L, Pérol D, Ginestet C, Falchero L, Arpin D, Vincent M, et al. A prospective study on radiation pneumonitis following conformal radiation therapy in non-small-cell lung cancer: clinical and dosimetric factors analysis. Radiother Oncol (2004) 71:175-81. doi:10.1016/j.radonc.2004.02.005

91. Marks LB, Bentzen SM, Deasy JO, Kong FM, Bradley JD, Vogelius IS, et al. Radiation dose-volume effects in the lung. Int J Radiat Oncol Biol Phys (2010) 76:S70-6. doi:10.1016/j.ijrobp.2009.06.091

92. Seppenwoolde Y, Lebesque JV, de Jaeger K, Belderbos JS, Boersma LJ, Schilstra $\mathrm{C}$, et al. Comparing different NTCP models that predict the incidence of radiation pneumonitis. Normal tissue complication probability. Int J Radiat Oncol Biol Phys (2003) 55:724-35. doi:10.1016/S0360-3016(02)03986-X

93. Pauwels S, Barone R, Walrand S, Borson-Chazot F, Valkema R, Kvols LK, et al. Practical dosimetry of peptide receptor radionuclide therapy with (90)Ylabeled somatostatin analogs. J Nucl Med (2005) 46(Suppl 1):92S-8S.

94. Therasse P, Arbuck SG, Eisenhauer EA, Wanders J, Kaplan RS, Rubinstein L, et al. New guidelines to evaluate the response to treatment in solid tumors. European Organization for Research and Treatment of Cancer, National Cancer Institute of the United States, National Cancer Institute of Canada. J Natl Cancer Inst (2000) 92:205-16. doi:10.1093/jnci/92.3.205
95. Eisenhauer EA, Therasse P, Bogaerts J, Schwartz LH, Sargent D, Ford R, et al. New response evaluation criteria in solid tumours: revised RECIST guideline (version 1.1). Eur J Cancer (2009) 45:228-47. doi:10.1016/j.ejca.2008.10.026

96. Bruix J, Sherman M, Llovet JM, Beaugrand M, Lencioni R, Burroughs AK, et al. Clinical management of hepatocellular carcinoma. Conclusions of the Barcelona-2000 EASL conference. European Association for the Study of the Liver. J Hepatol (2001) 35:421-30. doi:10.1016/S0168-8278(01)00130- 1

97. Tai A, Erickson B, Khater KA, Allen X. Estimate of radiobiologic parameters from clinical data for biologically based treatment planning for liver irradiation. Int J Radiat Oncol Biol Phys (2008) 70:900-7. doi:10.1016/j.ijrobp.2007.10.037

98. Lencioni R, Llovet JM. Modified RECIST (mRECIST) assessment for hepatocellular carcinoma. Semin Liver Dis (2010) 30:52-60. doi:10.1055/s-00301247132

99. Marks LB, Yorke ED, Jackson A, Ten Haken RK, Constine LS, Eisbruch A, et al. Use of normal tissue complication probability models in the clinic. Int J Radiat Oncol Biol Phys (2010) 76(3 Suppl):S10-9. doi:10.1016/j.ijrobp.2009. 07.1754

100. Sarfaraz M, Kennedy AS, Cao ZJ, Sackett GD, Yu CX, Lodge MA, et al. Physical aspects of yttrium-90 microsphere therapy for nonresectable hepatic tumors. Med Phys (2003) 30:199-203. doi:10.1118/1.1538235

101. Sangro B, Bilbao JI, Boan J, Martinez-Cuesta A, Benito A, Rodriguez J, et al. Radioembolization using 90Y-resin microspheres for patients with advanced hepatocellular carcinoma. Int J Radiat Oncol Biol Phys (2006) 66:792-800. doi:10.1016/j.ijrobp.2006.05.065

102. Lau WY, Ho S, Leung TW, Chan M, Ho R, Johnson PJ, et al. Selective internal radiation therapy for nonresectable hepatocellular carcinoma with intraarterial infusion of 90yttrium microspheres. Int J Radiat Oncol Biol Phys (1998) 40:583-92. doi:10.1016/S0360-3016(97)00818-3

Conflict of Interest Statement: The editorial costs of the paper submitted will be payed by the SIR-Spheres company.

Received: 03 April 2014; paper pending published: 17 June 2014; accepted: 23 July 2014; published online: 19 August 2014.

Citation: Cremonesi $M$, Chiesa C, Strigari L, Ferrari M, Botta F, Guerriero F, De Cicco C, Bonomo G, Orsi F, Bodei L, Di Dia A, Grana CM and Orecchia R (2014) Radioembolization of hepatic lesions from a radiobiology and dosimetric perspective. Front. Oncol. 4:210. doi: 10.3389/fonc.2014.00210

This article was submitted to Cancer Imaging and Diagnosis, a section of the journal Frontiers in Oncology.

Copyright (C) 2014 Cremonesi, Chiesa, Strigari, Ferrari, Botta, Guerriero, De Cicco, Bonomo, Orsi, Bodei, Di Dia, Grana and Orecchia. This is an open-access article distributed under the terms of the Creative Commons Attribution License (CC BY). The use, distribution or reproduction in other forums is permitted, provided the original author(s) orlicensor are credited and that the original publication in this journal is cited, in accordance with accepted academic practice. No use, distribution or reproduction is permitted which does not comply with these terms. 